\title{
Wellington Andraus
}

\section{Estudo do efeito da S-nitroso-N-acetilcisteína na lesão de isquemia/reperfusão em fígado esteatótico de ratos}

\author{
Tese apresentada à Faculdade de Medicina da \\ Universidade de São Paulo para obtenção do título \\ de Doutor em Ciências
}

Área de concentração: Clínica Cirúrgica

Orientador: Prof. Dr. Marcel Cerqueira Cesar Machado

São Paulo 
Dados Internacionais de Catalogação na Publicação (CIP)

Preparada pela Biblioteca da

Faculdade de Medicina da Universidade de São Paulo

Creprodução autorizada pelo autor

\section{Andraus, Wellington}

Estudo do efeito da S-nitroso-N-acetilcisteína na lesão de isquemia/reperfusão em fígado esteatótico de ratos / Wellington Andraus. -- São Paulo, 2007.

Tese(doutorado)--Faculdade de Medicina da Universidade de São Paulo. Departamento de Cirurgia.

Área de concentração: Clínica Cirúrgica.

Orientador: Marcel Cerqueira Cesar Machado.

Descritores: 1.Fígado gorduroso 2.Compostos nitrosos 3.Acetilcisteína 4.Traumatismo por reperfusão 5.Estresse oxidativo 6.Ratos

USP/FM/SBD-183/07 
Dedico este trabalho aos meus pais, Jurjus e Sebastiana, que dedicaram suas vidas aos seus filhos. Aos meus irmãos, Marta, Luiz e Kleber, que sempre me apoiaram em todos os momentos.

E também à Luciana, que esteve sempre ao meu lado durante todo este trabalho. 


\title{
AGRADECIMENTO ESPECIAL
}

\author{
À Luciana Bertocco de Paiva Haddad pela contribuição essencial para a \\ elaboração da tese, direta e indiretamente, e pelo amor, dedicação e \\ companheirismo em todos os momentos.
}




\section{AGRADECIMENTOS}

Ao Prof. Dr. Marcel Cerqueira Cesar Machado pela orientação rigorosa na condução desta tese, pela confiança depositada, e pelos ensinamentos em minha formação pessoal e profissional.

Ao Prof. Dr. Telesforo Bacchella pelo exemplo, pela contribuição, apoio e ensinamentos em minha carreira profissional.

Ao Prof. Marcelo Ganzarolli de Oliveira pela grande contribuição através de seu laboratório e também na realização desta tese.

Às amigas Ana Maria de Mendonça Coelho, responsável pelo laboratório LIM 37 onde foi realizado a pesquisa, e Sandra Nassa Sampietre pela amizade antes de tudo, e também pela colaboração irrestrita, trabalho árduo e disponibilidade imprescindíveis à realização deste trabalho.

À Dra. Regina Leitão pela sua irrestrita colaboração na realização dos estudos histológicos.

Às amigas Eliane Falcone Monico Gazetto e Mariliza Ottani Fernandes da Silva pela amizade, solicitude e colaboração indispensável.

À Sra. Violeta Kubrusly pela grande colaboração na correção de português deste trabalho.

Às amigas Nilza Aparecida Trindade Molan, Márcia Saldanha Kubrusly e Marta Bellodi Privato pela colaboração, apoio e amizade oferecidos.

Aos amigos do serviço de transplante de fígado Prof. Dr. Marcel Autran Cesar Machado, Dr. Rodrigo Bronze de Martino, Dr. Fábio Ferrari Makdissi, Dr. Vinicius Rocha Santos, Dr. Estela Regina Ramos Figueira, Dr. André Cosme de 
Oliveira, Dr. Antônio Roberto F. Teixeira, Dr. Roberto Ferreira Meirelles Junior, Dr. Flávio Henrique Ferreira Galvão, Dr. Edson Abdala, Dra. Patricia Rodrigues Bonazzi, Dr. Maurício Fernandes de Almeida Barros, Dr. Hoel Sette Júnior, Márcia Rached Esper Kallas, Alberto Queiroz Farias, Celso Eduardo Lourenço Matielo, João Plínio S. Rocha, Joel Avancini Rocha Filho, Ricardo Souza Nani, Julio Cesar Acosta Navarro, Rodrigo Conada Trofo Surjan, Ailton Araújo Sepulveda Júnior e Fábio Moura pela amizade sincera, convivência harmoniosa, apoio irrestrito, compreensão e auxílio nos momentos de necessidade.

A todos os amigos da Disciplina de Cirurgia e Transplante de Fígado Adriana Cortez, Andreza de Moraes, Cristiane Prestes da Rosa, Cristiane Silva de Souza, Daniele Siqueira Campos, Francisco Lúcio Silva Filho, Jézio Vieira Carvalho, Karina Tiemi Osaki, Maria das Graças David, Maria Patrícia Silva, Rosilda Nunes Pontes, Valcinéia Souza Andrade Gaspar, Valdecy Miranda Barbosa, Alcione Sanches Alexandre, Ana Lucia Bernares, Tatiana Zanesco, Daniela Smid, Dorotéia Silva Freitas, Genilton Serejo Mesquita, Genivaldo Silva, Isabel Leal, Izamilda Firmino da Silva, Lucimar Fabrizio Tirone da Silva, Marco Antonio de Paulo Júnior, Maria Goreth P. da Silva, Maria Ines de Oliveira, Natali Nathane da Silva, Norma Oliveira Maia, Reginaldo de Almeida Andrade, Rita Ruschioni de Oliveira, Silvana Figueiredo Guido e Vitor Alonso Gonçalves pela amizade, colaboração diária e convivência harmoniosa. 


\section{SUMÁRIO}

RESUMO

SUMMARY

1 - INTRODUÇÃO --- 1

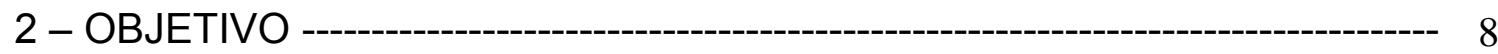

3 - MATERIAL E MÉTODOS --

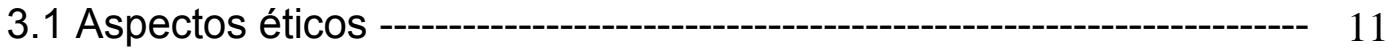

3.2 Material ------------------------------------------------------------------- 11

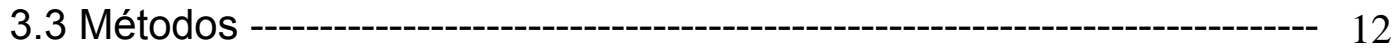

3.3.1 Grupos do experimento ----------------------------------- 12

3.3.2 Indução da esteatose ------------------------------- 12

3.3.3 Indução da isquemia e reperfusão hepáticas----------------- 13

3.3.4 Coleta de material para análise ------------------- 16

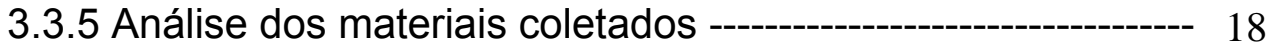

3.3.5.1 Avaliação da permeabilidade vascular pulmonar--- 18

3.3.5.2 Respiração mitocondrial ---------------------- 18

3.3.5.3 Atividade da mieloperoxidase pulmonar ------------ 19

3.3.5.4 Histologia ---------------------------------- 20

3.3.5.5 Análises bioquímicas----------------------------- 21

3.3.5.6 Avaliação da peroxidação lipídica--------------------- 21

3.3.6 Análise estatística ---------------------------------- 22

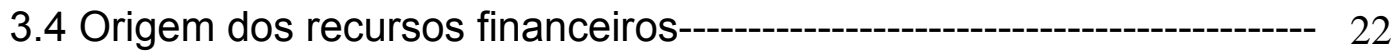

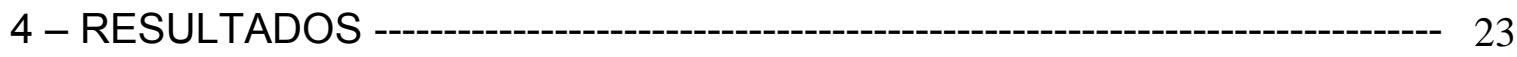

4.1 Efeito da esteatose na lesão de isquemia e reperfusão------------- 24

4.2 Efeito da SNAC na lesão de isquemia e reperfusão em ratos com

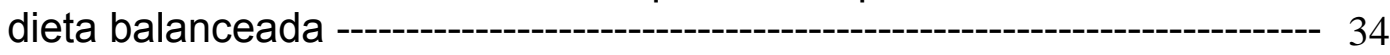

4.3 Efeito da SNAC na lesão de isquemia e reperfusão em ratos com esteatose acentuada------------------------- 36

4.4 Efeito da isquemia e reperfusão hepática parcial na porção não

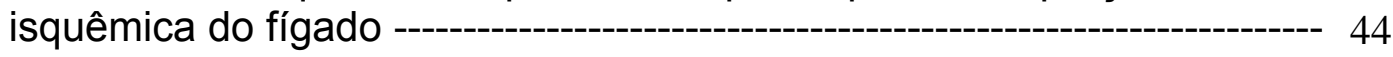

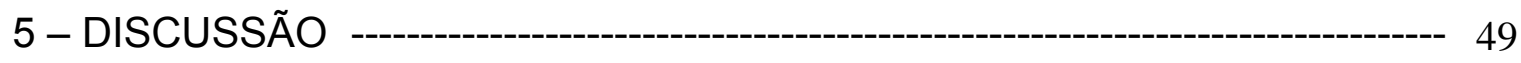

6 - CONCLUSÕES -

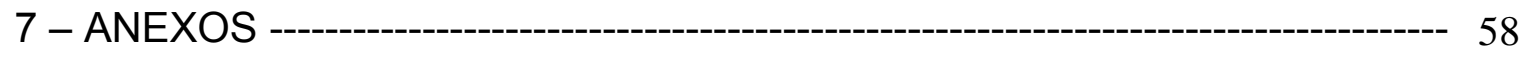

8 - REFERÊNCIAS BIBLIOGRÁFICAS - 


\section{RESUMO}

Andraus W. Estudo do efeito da S-nitroso-N-acetilcisteína na lesão de isquemia/reperfusão em fígado esteatótico de ratos [tese]. São Paulo: Faculdade de Medicina, Universidade de São Paulo;2007. 77p.

INTRODUÇÃO: A esteatose é a doença hepática crônica mais frequente na população. Seus efeitos lesivos hepáticos podem adicionar-se aos efeitos da isquemia e reperfusão $(I / R)$ nos transplantes de fígado e cirurgias hepáticas. Em ambos, o estresse oxidativo e o dano na microcirculação são importantes fatores na gênese da lesão hepática. Vários antioxidantes já foram testados em modelos experimentais de esteatose e I/R e mostraram benefício, entre eles a $\mathrm{N}$-acetilcisteína (NAC). O óxido nítrico (NO) tem efeito controverso sobre a lesão de $\mathrm{I} / \mathrm{R}$, entretanto em baixas doses pode ser benéfico à microcirculação hepática. A S-nitroso-Nacetilcisteína (SNAC) fornece a NAC e também NO. Esta droga foi testada mostrando benefício em modelos experimentais de esteatose e $\mathrm{I} / \mathrm{R}$ de músculo esquelético. Contudo, ainda não foi testada na lesão de I/R em fígados esteatóticos. MÉTODOS: Foram estudados 34 ratos machos Wistar divididos em 4 grupos: grupo I $(n=8)$ - sem esteatose tratados com solução salina; grupo II $(n=8)$ - sem esteatose tratados com SNAC; grupo III $(n=9)$ - com esteatose tratados com solução salina; grupo IV $(n=9)$ - com esteatose tratados com SNAC. A indução da esteatose foi realizada com dieta aproteica. Os animais foram submetidos a isquemia hepática parcial $(70 \%)$ por um período de 1 hora e um período de reperfusão de 4 horas. A droga foi administrada por via intraperitoneal. Foram avaliados histologia, respiração mitocondrial e estresse oxidativo (MDA) hepáticos, transaminases séricas e mieloperoxidase e extravasamento do corante azul de Evans pulmonares. RESULTADOS: Não houve diferença entre os grupos I e II em todas as variáveis avaliadas (histologia, função mitocondrial (RCR e ADP/O), transaminases (AST e ALT), azul de Evans e mieloperoxidase pulmonares), encontrando-se apenas uma tendência a menor estresse oxidativo (MDA) $(p=0,07)$ no fígado isquêmico do grupo tratado (grupo II). A comparação entre os grupos III e IV não encontrou diferença nas transaminases (AST e ALT), e no azul de Evans e mieloperoxidase pulmonares. $O$ grupo IV (esteatose e SNAC) apresentou no fígado isquêmico menor hemorragia intraparenquimatosa $(p=0,02)$, melhor função mitocondrial $(R C R)(p=0,01)$ $(A D P / O) \quad(p=0,01)$, e menor estresse oxidativo (MDA) $(p=0,007)$ quando comparado com o grupo não tratado (grupo III). CONCLUSÕES: Neste modelo, o tratamento com SNAC não melhora a lesão de I/R em ratos sem esteatose. No entanto, a SNAC melhora a lesão hepática pós I/R em ratos com fígado esteatótico.

Descritores: 1.Fígado gorduroso 2.Compostos nitrosos 3.Acetilcisteína 4.Traumatismo por reperfusão 5.Estresse oxidativo 6.Ratos 


\section{SUMMARY}

Andraus W. Study of S-nitroso-N-acetylcysteine effect on ischemia/reperfusion lesion in steatotic livers of rats [thesis]. São Paulo: "Faculdade de Medicina, Universidade de São Paulo"; 2007. 77p.

BACKGROUND: Steatosis is the most frequent chronic liver disease in general population. Steatosis can make ischemia/reperfusion (I/R) lesions worse in liver transplants and hepatic surgeries. Oxidative stress and hepatic microcirculatory damage are related to generation of steatosis and I/R lesions. Several antioxidant drugs, for example the $\mathrm{N}$-acetylcysteine (NAC), have been already used in steatotic and $\mathrm{I} / \mathrm{R}$ experimental models, and showed better outcome in treated groups. The nitric oxide (NO) has controversial effects on I/R, however, in low doses it can improve hepatic microcirculation. The S-nitroso-N-acetylcysteine (SNAC) releases NAC and NO. It ameliorated oxidative stress in experimental models of steatosis and skeletal muscle I/R. In contrast, this drug has never been used in steatotic liver I/R. METHODS: thirty four male Wistar rats were studied and divided in four groups: group I $(n=8)$ - without steatosis and treated with saline solution; group II $(n=8)-$ without steatosis and treated with SNAC; group III $(n=9)$ - with steatosis and treated with saline solution; group IV $(n=9)$ - with steatosis treated with SNAC. Aproteic diet was used for steatosis induction. The animals underwent a partial hepatic ischemia (70\%) for 1 hour and reperfusion for 4 hours. The drug was administrated intraperitoneally. The parameters evaluated were hepatic histology, mitochondrial respiration and oxidative stress (MDA), seric transaminasis and pulmonary mieloperoxidasis and Evans blue extravasation. RESULTS: There were not any difference between groups I and II in all parameters evaluated (histology, mithocondrial function (RCR and ADP/O), transaminasis (AST and ALT), pulmonary Evans blue extravasation and mieloperoxidasis), and it showed only tendency of less oxidative stress (MDA) $(p=0,07)$ in ischemic liver of treated group (group II). The comparison between groups III and IV didn't show any difference in transaminasis (AST and ALT), pulmonary Evans blue and mieloperoxidasis. Group IV (steatosis and SNAC) showed in the ischemic liver lower intraparenchymatous hemorrhage $(p=0,02)$, better mitochondrial function (RCR) $(p=0,01)$ and $(A D P / O)(p=0,01)$, and less oxidative stress (MDA) $(p=0,007)$ when compared with untreated group (group III). CONCLUSIONS: Based on this experimental model, SNAC treatment shows no benefit in non steatotic I/R lesion, however, in steatotic rats, SNAC ameliorates hepatic lesions post I/R.

Descriptors: 1.Fatty liver 2.Nitroso compounds 3.Acetylcysteine 4. Reperfusion injury 5.Oxidative stress 6.Rats 
1 - INTRODUCCÃO 


\section{INTRODUCÃO}

A esteatose é a doença hepática crônica mais freqüente na população. Uma análise de fígados em autópsia de 503 pacientes encontrou $24 \%$ de esteatose ${ }^{1}$. Outros trabalhos verificaram esta alta prevalência de esteatose hepática: $31 \%$ em adultos nos EUA avaliados por ressonância magnética ${ }^{2}$ e $33 \%$ em potenciais doadores vivos submetidos à biópsia hepática ${ }^{3}$. Esta prevalência aumenta com a idade, variando de $2,6 \%$ entre crianças a $26 \%$ entre adultos com 40 a 59 anos. ${ }^{4,5}$ Os principais fatores de risco para a esteatose hepática são o diabetes e a obesidade, com prevalência de $50 \%$ e $76 \%$ de esteatose nestas condições respectivamente, e de praticamente $100 \%$ quando os 2 fatores estão associados. ${ }^{6,7,8}$

A esteatose hepática está intimamente relacionada com a função mitocondrial. Ela ocorre tanto como conseqüência do prejuízo da $\beta$-oxidação mitocondrial, que leva ao acúmulo de ácidos graxos livres na forma de triglicérides no citosol dos hepatócitos, ${ }^{9}$ como pode ser a causa desta disfunção levando a alterações estruturais e funcionais nesta organela. ${ }^{10} \mathrm{~A}$ presença de esteatose no fígado pode provocar uma reação inflamatória. Especula-se que para que o fígado esteatótico comece a apresentar hepatite seja necessário um gatilho, ou seja, algum fator associado, dentre os quais podemos citar: citocinas relacionadas a obesidade (TNF a, leptina, adiponectina), ácidos graxos livres, disfunção mitocondrial, endotoxina bacteriana e alterações microvasculares, e estes fatores podem ser diretamente tóxicos ou produzir estresse oxidativo. ${ }^{11,12,13,14,15}$

Neste mesmo contexto, o início da era de transplante de órgãos e de cirurgias hepáticas maiores impôs aos portadores de esteatose alterações sistêmicas e teciduais provocadas pela reação à isquemia e reperfusão hepáticas (I/R). Em 
nosso meio, já no início da década de 1970, iniciam-se trabalhos experimentais para a avaliação das conseqüências da I/R hepáticas, e desde o princípio encontraram-se alterações metabólicas sistêmicas e na microcirculação hepática. ${ }^{16,17,18}$ Sabe-se hoje que, nestas condições, xantina desidrogenase é convertida em xantina oxidase, que utiliza oxigênio como substrato. Durante a isquemia o consumo aumentado de ATP leva ao acúmulo de catabólitos purínicos de xantina e hipoxantina, os quais, após a reperfusão e na presença de oxigênio, são metabolizados pela xantina oxidase produzindo enormes quantidades de radicais superóxido e peróxido de hidrogênio. ${ }^{19}$ A liberação de radicais livres de oxigênio e TNF-a irão provocar lesões locais e a distância (figuras 1e 2).20,21,22,23

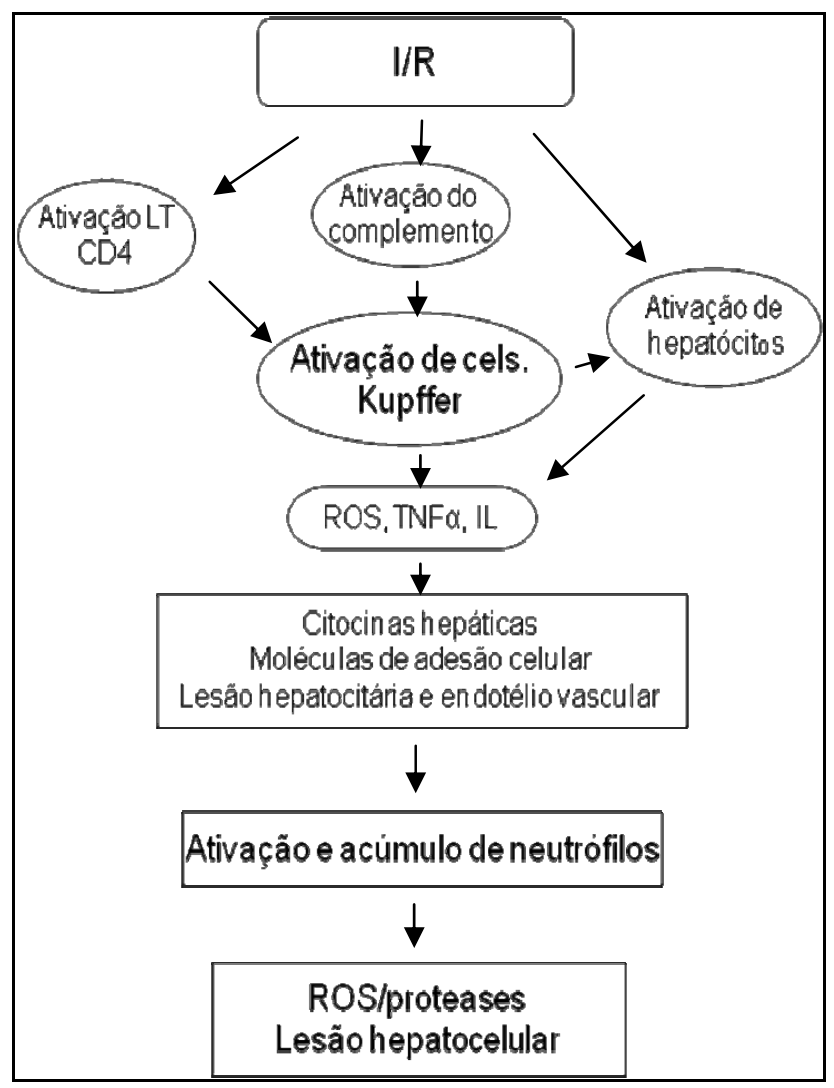

Figura 1: Esquema representando a cascata de reações pós isquemia e reperfusão hepáticas que culminam com a lesão hepatocelular. I/R, isquemia e reperfusão; LT, linfócitos T; cels,células; ROS, espécies reativas de oxigênio; TNF $\alpha$, fator de necrose tumoral $\alpha$; IL, interleucinas. 


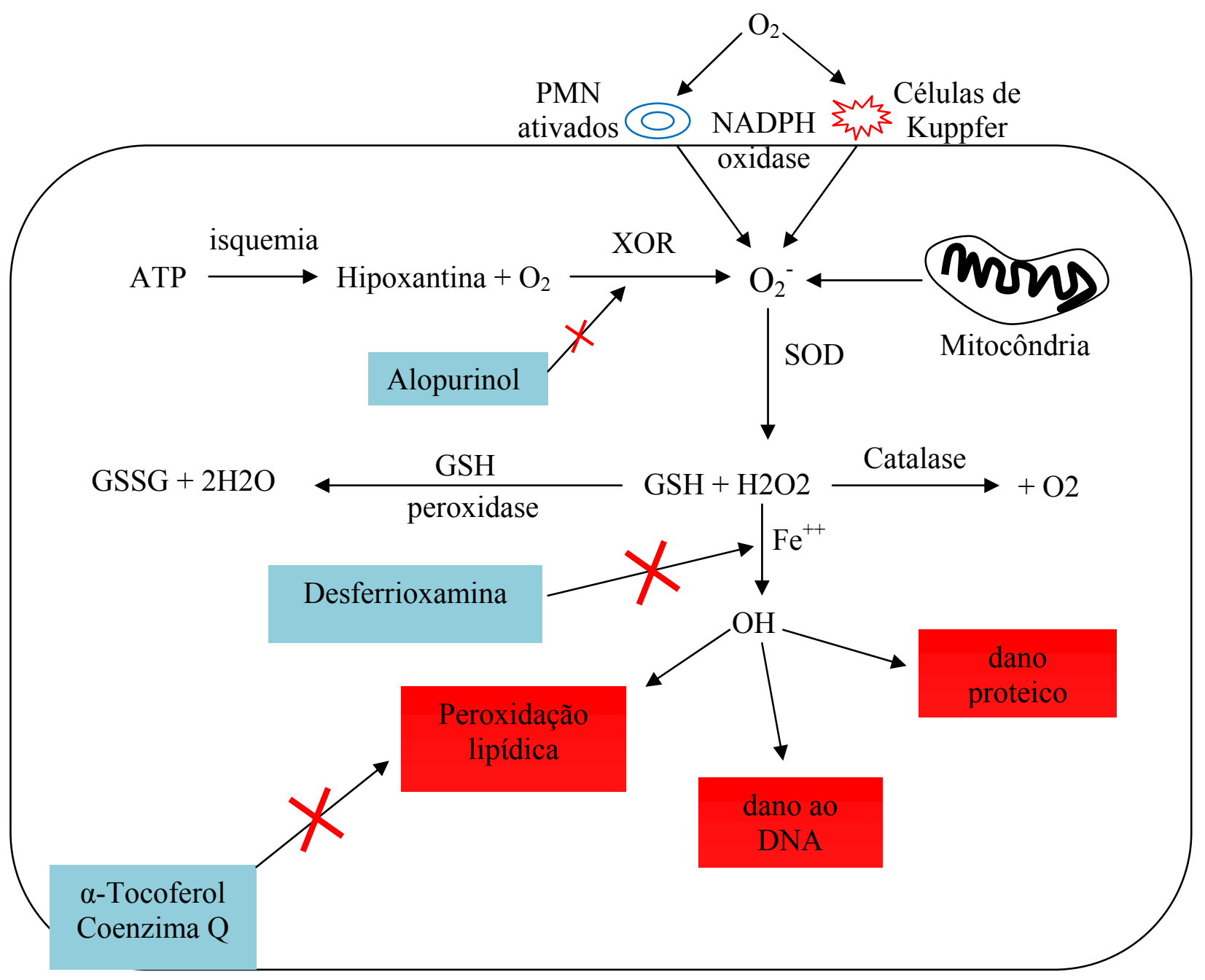

Figura 2: Mecanismos básicos do sistema antioxidante endógeno intracelular. Esquema adaptado de Glantzounis et $a l,{ }^{24}$ mostra os passos intracelulares que levam à produção de radicais livres de oxigênio e substâncias que atuam nestas reações. Os principais antioxidantes intracelulares são: enzima superóxido dismutase (SOD), catalase e glutationa (GSH) peroxidase. O a-tocoferol e coenzima $Q$ são os principais antioxidantes de membrana celular. PMN, células polimorfonucleares; NADPH, nicotinamida adenina dinucleotídeo fosfato; GSSG, glutationa dissulfida (glutationa oxidada); XOR, xantina oxidoredutase. 
Estes dois fatores potencialmente hepatotóxicos, esteatose e lesão de l/R, encontram-se frequentemente associados devido a alta prevalência de esteatose na população e ao grande número, na atualidade, de transplantes de fígado e cirurgias hepáticas. Nas hepatectomias, onde frequentemente realiza-se clampeamento do hilo hepático (manobra de Pringle), alguns autores mostraram pior evolução pósoperatória em pacientes com esteatose hepática, e identificaram a esteatose como fator de risco independente para complicações pós operatórias. ${ }^{25,26,27} \mathrm{Da}$ mesma forma, no transplante de fígado a esteatose também tem se mostrado fator potencializador da lesão de I/R. Vários trabalhos experimentais demonstraram aumento do estresse oxidativo associado a irregularidade de sinusóides e adesão de células inflamatórias no endotélio hepático, menor síntese de ATP após reperfusão e menor sobrevida pós transplante, todos em animais com enxertos esteatóticos. ${ }^{20,21,22,23,28} \mathrm{Em}$ adição, a membrana plasmática de hepatócitos com esteatose apresentou maior permeabilidade após isquemia fria, sendo mais vulnerável às alterações de osmolaridade que podem ocorrer durante esta fase no transplante de fígado. ${ }^{29}$ Trabalhos clínicos em transplante de fígado também encontraram pior evolução na presença de esteatose hepática, mostrando uma relação com o não funcionamento primário do enxerto ("primary non function”), disfunção parcial do enxerto pós transplante e menor perfusão hepática após revascularização. ${ }^{30,31}$

Os prováveis mecanismos pelos quais a lesão de I/R torna-se mais intensa no fígado esteatótico têm sido muito estudados. Existem trabalhos que demonstram alterações no fígado esteatótico, mesmo antes da I/R, como alteração na microcirculação, com diminuição do número de sinusóides. ${ }^{13,28,29,31,32}$ Além disso, a disfunção mitocondrial tem sido citada como um importante fator na menor tolerância 
hepática pós I/R em fígados esteatóticos. ${ }^{13,29,33}$ Os ácidos graxos nos hepatócitos provocam um efeito inibitório na produção de acetil coenzima $A$, que é um importante precursor no ciclo de Krebs e na gluconeogênese, levando a uma menor formação de ATP. 9,13,29,34

O estresse oxidativo aumentado, com a presença de radicais livres levando a lipoperoxidação das membranas celulares, também tem sido implicado na pior evolução dos fígados esteatóticos. ${ }^{21,23,24}$ Há um acúmulo de neutrófilos, que desempenham papel importante na liberação de radicais livres. ${ }^{21,35}$ Foram também detectados menores níveis de glutationa reduzida em fígados esteatóticos pós I/R demonstrando o aumento do estresse oxidativo nestes casos.

As reações que levam à produção de radicais livres podem ser minimizadas ou bloqueadas por moléculas denominadas antioxidantes, que podem atuar em diversos passos destas reações (figura 2). A suplementação de diversos antioxidantes foi testada em lesão de l/R em fígados esteatóticos mostrando melhora significativa. ${ }^{36,37,38}$ A N-acetilcisteína (NAC) é um dos antioxidantes que apresentou efeito protetor sobre o estresse oxidativo pós I/R em trabalhos experimentais ${ }^{36,39,40} \mathrm{e}$ também sobre o estresse oxidativo provocado por outras causas não isquêmicas como dieta hiperglicídica e icterícia obstrutiva. ${ }^{41,42}$

A S-nitroso-N-acetilcisteína (SNAC) (figura 3) é uma droga nova, com início de testes experimentais relativamente recente, e que após sua administração promove liberação de NAC e óxido nítrico (NO). O último, por sua vez, tem ação vasodilatadora sistêmica e tecidual, atuando também na microcirculação hepática. ${ }^{43}$ Especula-se que o NO poderia atuar de maneira benéfica na microcirculação hepática, cujas alterções são importantes na fisiopatologia da lesão de $\mathrm{I} / \mathrm{R}$ em fígados esteatóticos. Seu outro componente, a N-acetilcisteína (NAC), fornece um 
dos aminoácidos precursores da glutationa, um antioxidante endógeno de reconhecida ação benéfica na lesão causada pelo estresse oxidativo.

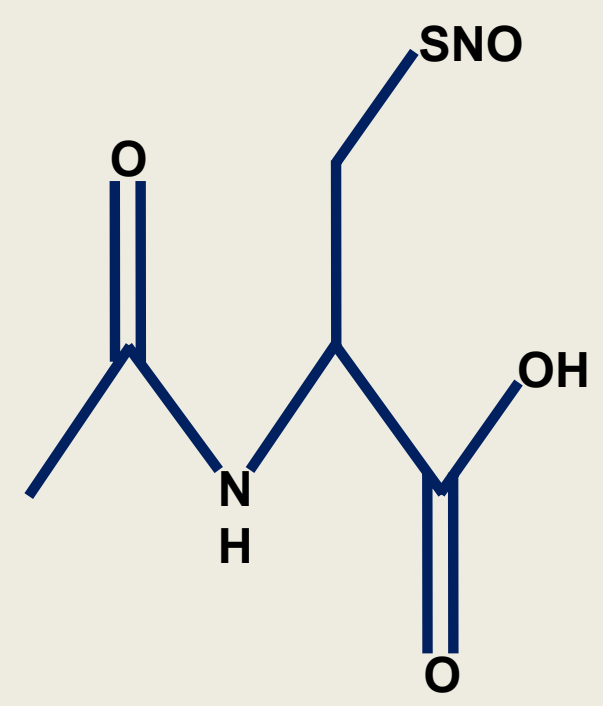

Figura 3: Composição química da S-nitroso-N-acetilcisteína.

A SNAC foi testada em modelos experimentais mostrando benefício naqueles com estresse oxidativo aumentado, como em ratos com hipercolesterolemia, esteatose hepática e também lesão de I/R em músculo esquelético. ${ }^{44,45,46}$ Entretanto a SNAC ainda não foi testada na lesão de I/R hepática em fígados esteatóticos. 
8

2 - OBJETIVO 
2. OBJETIVO

O objetivo deste trabalho é avaliar os efeitos da administração de S-nitroso-Nacetilcisteína sobre a lesão de isquemia e reperfusão em fígado esteatótico de ratos. 


\section{3 - MATERIAL E MÉTODOS}




\section{MATERIAL E MÉTODOS}

\subsection{Aspectos Éticos}

O projeto foi aprovado pela Comissão de Ética do Hospital das Clínicas da Faculdade de Medicina da Universidade de São Paulo (CAPPesq, HC-FMUSP) e foram respeitadas as normas de proteção e cuidados para animais de experimentação, segundo o Guide for the Care and Use of Laboratory Animals. Institute of Laboratory Animal Resources, Comission on Life Sciences and National Research Council. National Academy Press, Washington, D.C., 1996.

\subsection{Material}

Os animais que foram utilizados neste projeto provêm do biotério da FMUSP, onde foram selecionados e acondicionados de acordo com as normas sanitárias estabelecidas.

Foram estudados 34 ratos machos Wistar, divididos em 4 grupos, mantidos em gaiolas no laboratório da Disciplina de Transplante e Cirurgia do Fígado, hidratados com água filtrada ad libitum e submetidos a períodos de 12 horas de claro e escuro e a temperatura ambiente de $23^{\circ} \mathrm{C}$. 


\subsection{Métodos}

\subsubsection{Grupos do experimento}

Trinta e quatro ratos do estudo foram divididos em 4 grupos, todos submetidos à I/R:

Grupo I ( $n=8)$ - ratos controle (dieta balanceada), tratados com solução salina.

Grupo II $(\mathrm{n}=8)$ - ratos com dieta balanceada, tratados com SNAC (S-nitroso-Nacetilcisteína).

Grupo III ( $n=9)$ - ratos com esteatose acentuada (dieta aproteica), tratados com solução salina.

Grupo IV $(n=9)$ - ratos com esteatose acentuada (dieta aproteica), tratados com SNAC.

\subsubsection{Indução da esteatose}

Para a indução de esteatose foi utilizada dieta aproteica, alimentando os grupos específicos por um período de 21 dias. Foi utilizado o mesmo método descrito em estudos experimentais realizados anteriormente em nosso meio. ${ }^{47,48} \mathrm{~A}$ composição para cada Kg de ração é de: caseína (0), maisena (910g), óleo de soja (50g), mistura vitamínica (AIN93M) $(0,2 \mathrm{~g})$, mistura de sais (AIN93M) $(40 \mathrm{~g})$.

Os ratos dos demais grupos também foram alimentados por um período igual com ração comercial balanceada. A dieta balanceada utilizada foi a comercial da 
marca Nuvilab: alimento equilibrado para camundongos e ratos de laboratório baseado nas recomendações do National Research Council e National Institute of Health.

\subsubsection{Indução da isquemia e reperfusão hepáticas}

Os animais foram anestesiados por via intraperitoneal com cloridrato de cetamina $5 \%$ (Ketalar®, Cristália), $30 \mathrm{mg} / \mathrm{kg}$ e cloridrato de xylazina 2\% (Rompum®, Bayer), $30 \mathrm{mg} / \mathrm{kg}$, submetidos à intubação orotraqueal com cateter $\mathrm{n}^{\circ} 16$ (Jelco®) e, à ventilação mecânica (Harvard Rodent Ventilator model 683, USA), com freqüência de $60 \mathrm{rpm}$ e volume corrente de $0,08 \mathrm{ml}$ por grama de peso.

Durante todo o procedimento, o animal foi aquecido com lâmpada halogênica de $45 \mathrm{~W}$ e $127 \mathrm{~V}$. A temperatura corpórea, monitorizada por termômetro retal digital (YSI Precision 4000A Thermometer, USA), foi mantida entre 35 e $37^{\circ} \mathrm{C}$ (figura 4 ).

Foi realizada laparotomia mediana estendendo-se por aproximadamente $4 \mathrm{~cm}$, à partir do apêndice xifóide. A isquemia hepática foi realizada parcialmente após isolamento e oclusão do pedículo hepático comum dos lobos mediano e ânterolateral esquerdo com pinça microvascular atraumática, permanecendo ocluído por 1 hora (figuras 5 e 6). Esta técnica evita a congestão intestinal permitindo a avaliação mais especifica das lesões dependentes da isquemia e reperfusão hepáticas. ${ }^{49,50}$

A incisão abdominal foi fechada para evitar a desidratação do animal. Após uma hora de isquemia quente, o abdômen foi reaberto e a pinça removida, permitindo a reperfusão dos lobos hepáticos isquêmicos. A incisão foi novamente fechada com sutura contínua com Mononylon® 4.0. 
A administração de SNAC, droga sintetizada e fornecida pelo Instituto de Química da Universidade Estadual de Campinas, sob orientação do Professor Marcelo Ganzarolli de Oliveira, foi iniciada 30 minutos após início da isquemia, e mantida por 1 hora (até 30 minutos após o término da isquemia), em infusão contínua intraperitoneal, no volume total de $1 \mathrm{ml} / 100 \mathrm{~g}$, na concentração de $100 \mathrm{nmol}$. O animal foi anestesiado com cloridrato de cetamina. Os grupos não tratados foram submetidos ao mesmo procedimento substituindo o SNAC por solução salina a $0,9 \%$ no mesmo volume e forma de administração. 


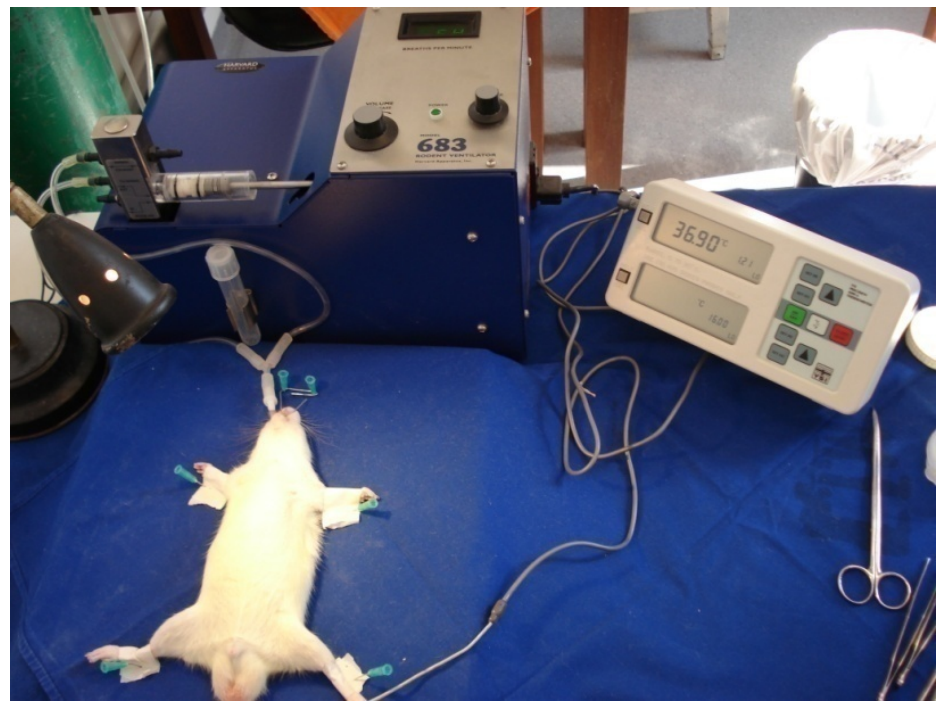

Figura 4: Rato anestesiado, com intubação orotraqueal, ventilação mecânica e controle de temperatura por termômetro retal antes de ser submetido à isquemia e reperfusão hepáticas.

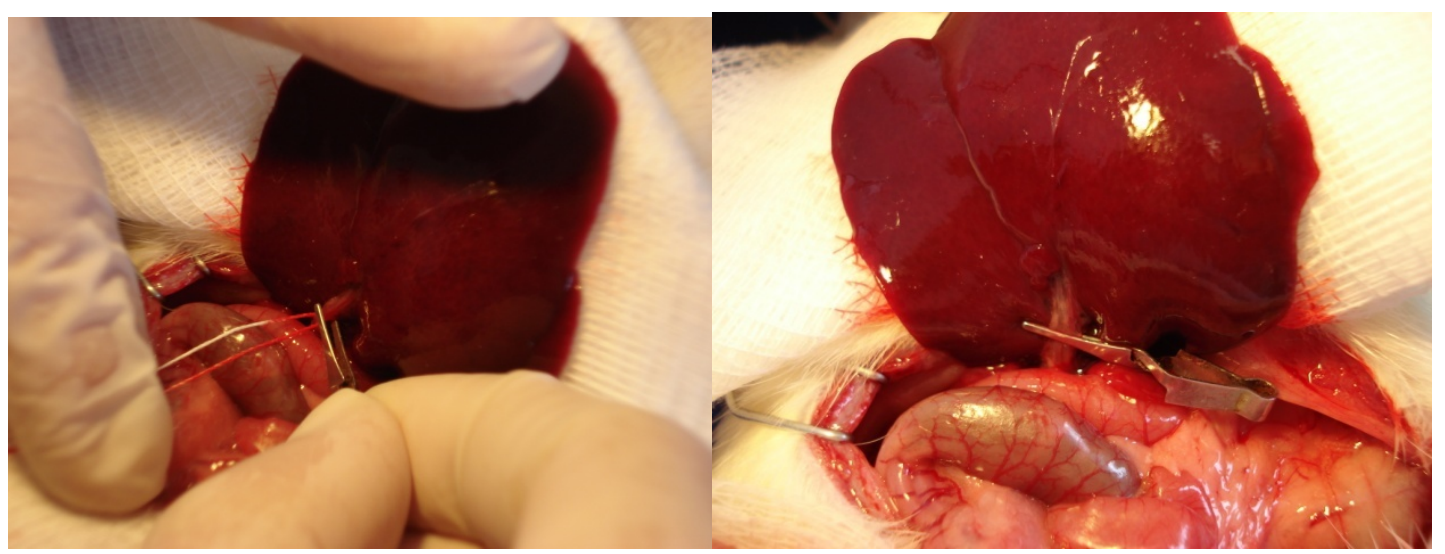

Figuras 5 e 6: Clampeamento do pedículo dos lobos hepáticos mediano e lateral direito com pinça vascular microcirúrgica. 


\subsubsection{Coleta de material para análise}

Depois da recuperação da anestesia, o cateter de intubação orotraqueal foi retirado e o animal permaneceu acondicionado em gaiola individual com água ad libitum por 4 horas. Após esse período, o rato foi novamente anestesiado com cloridrato de xylazina $2 \%$ (Rompum ${ }^{\circledR}$, Bayer), $40 \mathrm{mg} / \mathrm{kg}$ e a seguir, o corante azul de Evans (Sigma-Chemical Company, USA) foi injetado através da veia peniana na dose de $20 \mathrm{mg} / \mathrm{kg}$. Após 15 minutos foi realizada reabertura da parede abdominal e coleta de $5 \mathrm{~mL}$ de sangue por punção cardíaca. $\mathrm{O}$ animal foi sacrificado por secção da aorta e da veia cava inferior. O fígado foi removido e amostras dos lobos isquêmicos e não isquêmicos foram enviadas para avaliação histológica, avaliação da peroxidação lipídica pelo método que utiliza o ácido tiobarbitúrico (MDA) e para avaliação da respiração mitocondrial (figura 7). A artéria pulmonar foi cateterizada via ventrículo direito com cateter de 2,0 mm de diâmetro (Silastic, Dow Corning, $\mathrm{n}^{\circ}$ 602.175) para infusão de 30 a $50 \mathrm{~mL}$ de solução fisiológica, $10 \mathrm{ml} / \mathrm{min}$. O pulmão foi removido para a extração do corante azul de Evans e quantificação da mieloperoxidase tecidual (figura 8). O sangue foi enviado para a dosagem das transaminases (aspartato aminotransferase e alanina aminotransferase).

Após a conclusão desses procedimentos, o animal previamente sacrificado foi embalado em saco plástico branco para descarte de material biológico e incinerado em local apropriado. 


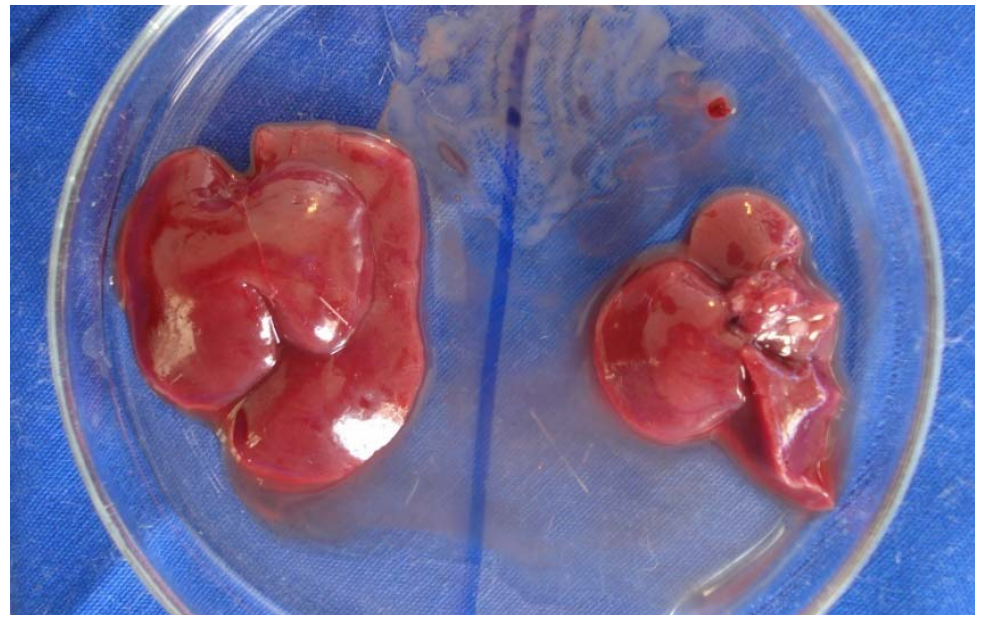

Figura 7: Fígado de rato coletado após o procedimento de isquemia e reperfusão, separados em porção isquêmica (à esquerda - $70 \%$ do volume total) e não isquêmica (à direita - $30 \%$ do volume total).

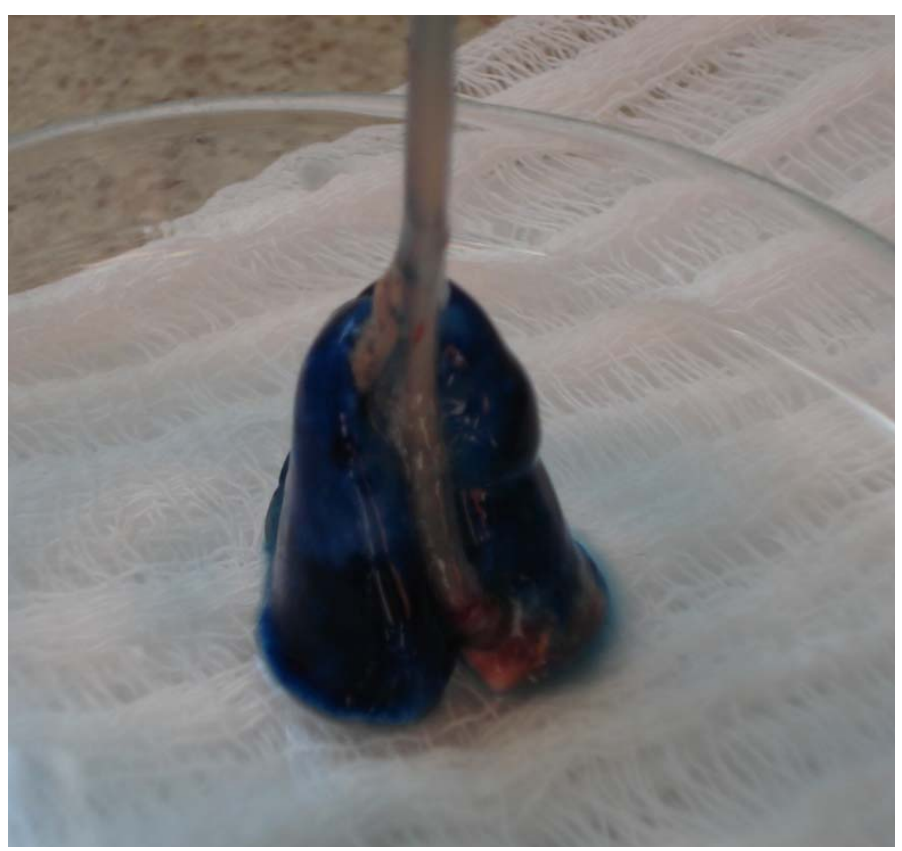

Figura 8: Pulmão de rato coletado após procedimento de isquemia e reperfusão e injeção do corante azul de Evans. 


\subsubsection{Análise dos materiais coletados :}

\subsubsection{Avaliação da permeabilidade vascular pulmonar}

A permeabilidade vascular pulmonar foi avaliada pela quantificação do corante azul de Evans extraído. Este, quando injetado na circulação, liga-se às proteínas séricas, principalmente à albumina. $\mathrm{O}$ processo inflamatório leva ao

aumento da permeabilidade capilar às macromoléculas, permitindo o extravasamento e deposição intersticial do complexo proteína-azul de Evans que é quantificado por espectrofotometria. ${ }^{51}$

Um fragmento do pulmão de cada animal foi utilizado para extração do azul de Evans. O corante foi extraído pela incubação dos fragmentos em tubos de ensaio com formamida (formamide, BDH Labs, England) na dose de $4 \mu \mathrm{g} / \mathrm{mg}$ de tecido, por 24 horas, em temperatura ambiente.

A quantidade de corante extraído do tecido foi determinada pelo espectrofotômetro com comprimento de onda de 620nm (Dynate MR 5000, Dynatec Laboratories, Inc. Biotecnology Products, Virginia, USA). Os resultados foram expressos em microgramas de azul de Evans por grama de tecido seco.

\subsubsection{Respiração mitocondrial}

A função mitocondrial hepática foi estudada nos lobos hepáticos isquêmicos e não isquêmicos dos animais imediatamente após estes terem sido retirados e 
imersos em solução de homogeneização. ${ }^{52}$ O consumo de oxigênio pelas mitocôndrias foi determinado polarograficamente, ${ }^{53}$ usando um oxígrafo $5 / 6 \mathrm{H}$ (Gilson Medical Eletronics, Inc) com eletrodo de $\mathrm{O}_{2}$ (Clarck, Yellow Springs Instruments Co., Yellow Springs, Ohio) a $28^{\circ} \mathrm{C}$.

Para a determinação do estado 4 (S4) da respiração (estado basal), as mitocôndrias recebem succinato de potássio como substrato energético. $O$ estado 3 (S3) da respiração (estado ativado) é induzido pela adição de adenosina difosfato (ADP, Sigma Chemical Company, St Louis, Missouri). Após todo o ADP ter sido fosforilado para ATP, S4 é medido novamente. A razão do controle respiratório (RCR - relação entre a velocidade de consumo de oxigênio na presença de ADP e a velocidade obtida após o gasto final de ADP) e a relação ADP/O (ADP/oxigênio) são calculadas como índices das funções oxidativas e fosforilativas das mitocôndrias. ${ }^{54}$

S3 e S4 serão expressos em nanogramas (ng) de átomos de oxigênio por miligrama de proteína mitocondrial por minuto determinada pelo método de Lowry et al. ${ }^{55}$

\subsubsection{Atividade da mieloperoxidase pulmonar}

A atividade da mieloperoxidase pulmonar (MPO) é utilizada como indicador da presença de neutrófilos seqüestrados no pulmão. $O$ ensaio é baseado em trabalhos publicados por Goldblum et $\mathrm{al}^{56} \mathrm{e}$ Warrem et al. $^{57}$ As amostras foram homogeneizadas com homogeneizador Polytron, usando tampão PBS contendo $0,5 \%$ de hexadecil e 5mM EDTA, $\mathrm{pH}$ 6,0. As amostras homogeneizadas foram 
submetidas ao ultrassom $(40 \mathrm{~Hz})$ e, posteriormente, centrifugadas a $3000 \mathrm{~g}$ por minuto. A atividade da MPO no sobrenadante foi quantificada através da densidade óptica (DO) a 490nm resultante da decomposição de $\mathrm{H}_{2} \mathrm{O}_{2}$ na presença de Odianisina. ${ }^{58}$ Os resultados foram expressos em DO a 490nm.

\subsubsection{Histologia}

Amostras do tecido hepático isquêmico e não isquêmico foram fixadas em solução de formol a $10 \%$ e submetidas a procedimentos de rotina para inclusão em parafina e análise à microscopia óptica de luz. Cortes de $5 \mu$ foram corados pela hematoxilina e eosina $(\mathrm{HE})$. A análise histológica foi feita por um único patologista sem conhecimento prévio dos grupos aos quais pertenciam as amostras. Foram estudadas as seguintes variáveis histopatológicas: tumefação hepatocelular, necrose hepatocelular coagulativa, hemorragia intraparenquimatosa, retração hepatocelular e presença de polimorfonucleares sinusoidais. Todas as variáveis histopatológicas mencionadas foram quantificadas seguindo um escore de 0 a 3: 0= ausente; 1 =focal ou leve; 2=moderada e 3=intensa.

Para a quantificação da esteatose foi utilizado o mesmo critério utilizado na prática clínica: classificação em esteatose micro e macrovesicular e quantificada seguindo o escore - $0=$ não detectada na amostra; 1 = presente em até $25 \%$ dos hepatócitos; 2= presente em até $50 \%$ dos hepatócitos; 3= presente em até $70 \%$ dos hepatócitos e 4= presente em mais de $80 \%$ dos hepatócitos. 


\subsubsection{Análises bioquímicas}

As transaminases, aspartato aminotransferase (AST) e alanina aminotransferase $(A L T)$, foram avaliadas como indicadores de lesão hepática. A quantificação de AST e ALT foi realizada pelo método ultravioleta otimizado (COBAS MIRA, Roche) de acordo com a International Federation of Clinical Chemistry. Os resultados foram expressos em unidades por litro (U/L).

\subsubsection{Avaliação da peroxidação lipídica}

As porções isquêmicas e não isquêmicas do fígado foram submetidas a quantificação de peroxidação lipídica pelo método que utiliza o ácido tiobarbitúrico (TBARS). Os tecidos $(100 \mathrm{mg} / \mathrm{ml}$ ) foram homogeneizados em tampão de $\mathrm{KCl}$ a $1,15 \%$, e centrifugados a $14000 \mathrm{~g}$ por 20 minutos. O sobrenadante foi armazenado a $-70^{\circ} \mathrm{C}$. Uma alíquota do sobrenadante foi adicionada a uma reação que utiliza $1,5 \mathrm{ml}$ de ácido tiobarbitúrico a 0,8\%, $200 \mu \mathrm{l}$ 8,1\% (v/v) SDS, 1,5 ml de ácido acético a 20\% (v/v), $\mathrm{pH}$ de 3,5 , e $600 \mu \mathrm{l}$ de água destilada, e aquecida a $90^{\circ} \mathrm{C}$ por 45 minutos. Após

o resfriamento à temperatura ambiente, as amostras foram separadas por centrifugação a $10000 \mathrm{~g}$ por 10 minutos, e sua absorbância medida por densidade óptica a $532 \mathrm{~nm}$, utilizando como padrão externo 1,1,3,3-tetrametroxipropano. A quantidade de peróxidos lipídicos foi mencionada como nmol de malondialdeido (MDA) equivalentes/mg de proteína. ${ }^{59}$ 


\subsubsection{Análise estatística}

Os resultados das dosagens do corante azul de Evans, do consumo de oxigênio pela mitocôndria, da atividade da mieloperoxidase pulmonar, das transaminases hepáticas (AST e ALT) e do MDA foram analisados pelo teste de ANOVA. Quando houve diferença estatística foi aplicado o teste de Tukey. ${ }^{60,61} \mathrm{O}$ t-teste foi utilizado para comparação dos grupos entre si. Valores de p menores ou iguais a 0,05 foram considerados significativos.

Os escores histológicos dos fígados analisados foram avaliados pelo teste de Kruskal-Wallis. Quando houve diferença estatística foi aplicado o teste de Dunn para análise dois a dois.

O poder do estudo foi calculado a partir dos resultados obtidos.

Para melhor transmitir a variabilidade e distribuição dos dados os resultados foram ilustrados em gráficos box-plot. Nestes gráficos o retângulo contém $50 \%$ da amostra, e a linha escura dentro do retângulo é a mediana. Os traços inferior e superior mostram os valores mínimo e máximo. Quanto maior o retângulo, maior a variabilidade do grupo.

Os valores individuais, média e desvio padrão para cada uma das variáveis de todos os grupos estão descritos nos anexos.

\subsection{ORIGEM DOS RECURSOS FINANCEIROS}

O trabalho foi desenvolvido no LIM-37 (Laboratório de Transplante e Cirurgia do Fígado) com recursos próprios do laboratório. 
4 - RESULTADOS 


\section{RESULTADOS}

\subsection{Efeito da esteatose na lesão de isquemia e reperfusão}

A comparação entre os grupos I (controle) (ratos com dieta balanceada e tratados com solução salina) e III (esteatose acentuada) (ratos com dieta aproteica e tratados com solução salina) mostrou: maiores valores de AST $(p<0,001)$ e ALT $(p<0,001)$ no grupo I (controle) (figura 9 e 10). Menor permeabilidade vascular pulmonar avaliada pela dosagem do corante azul de Evans $(p=0,04)$ (figura 11), como também menor valor de mieloperoxidase pulmonar $(p=0,05)$ no grupo I (controle) quando comparado com o grupo III (esteatose acentuada) (figura 12).

A análise histológica do fígado em cada grupo, com as porções isquêmicas e não isquêmicas em conjunto, encontrou esteatose significativamente maior $(p=0,001)$ nos grupos com dieta aproteica com uma média de $53,1 \% \pm 31,6$ nestes grupos quando comparados com os grupos com dieta balanceada que apresentaram $29,0 \% \pm 24,7$. Esta diferença, com maiores valores para os grupos com dieta aproteica, foi demonstrada não só para esteatose total, como também quando subdividida em esteatose micro $(p=0,001)$ e macrovesicular $(0,009)$ (figuras 13 e 14). O grupo com esteatose acentuada (grupo III) apresentou também hemorragia intraparenquimatosa mais intensa na porção isquêmica que o grupo controle (grupo I) $(p<0,001)$ (figura 15).

A função mitocondrial e o MDA foram estudados nas porções isquêmicas e não isquêmicas do fígado em todos os grupos. 
A comparação entre os grupos I e III na porção não isquêmica do fígado evidenciou: em relação à função mitocondrial, ausência de diferença significativa na função oxidativa $(R C R)(p=0,18)$, como também na função fosforilativa (ADP/O) $(p=0,18)$. Entretanto, mostrou grande aumento no estresse oxidativo medido pelo MDA no grupo com esteatose acentuada (grupo III) $(p=0,008)$ (figura 16).

A comparação entre os grupos I e III na porção isquêmica do fígado evidenciou: em relação à função mitocondrial, ausência de diferença significativa na função oxidativa (RCR) $(p=0,74)$, como também na função fosforilativa (ADP/O) $(p=0,89)$. Contudo evidenciou grande aumento no estresse oxidativo medido pelo MDA no grupo com esteatose acentuada (grupo III) $(p=0,007)$ (figura 17). 


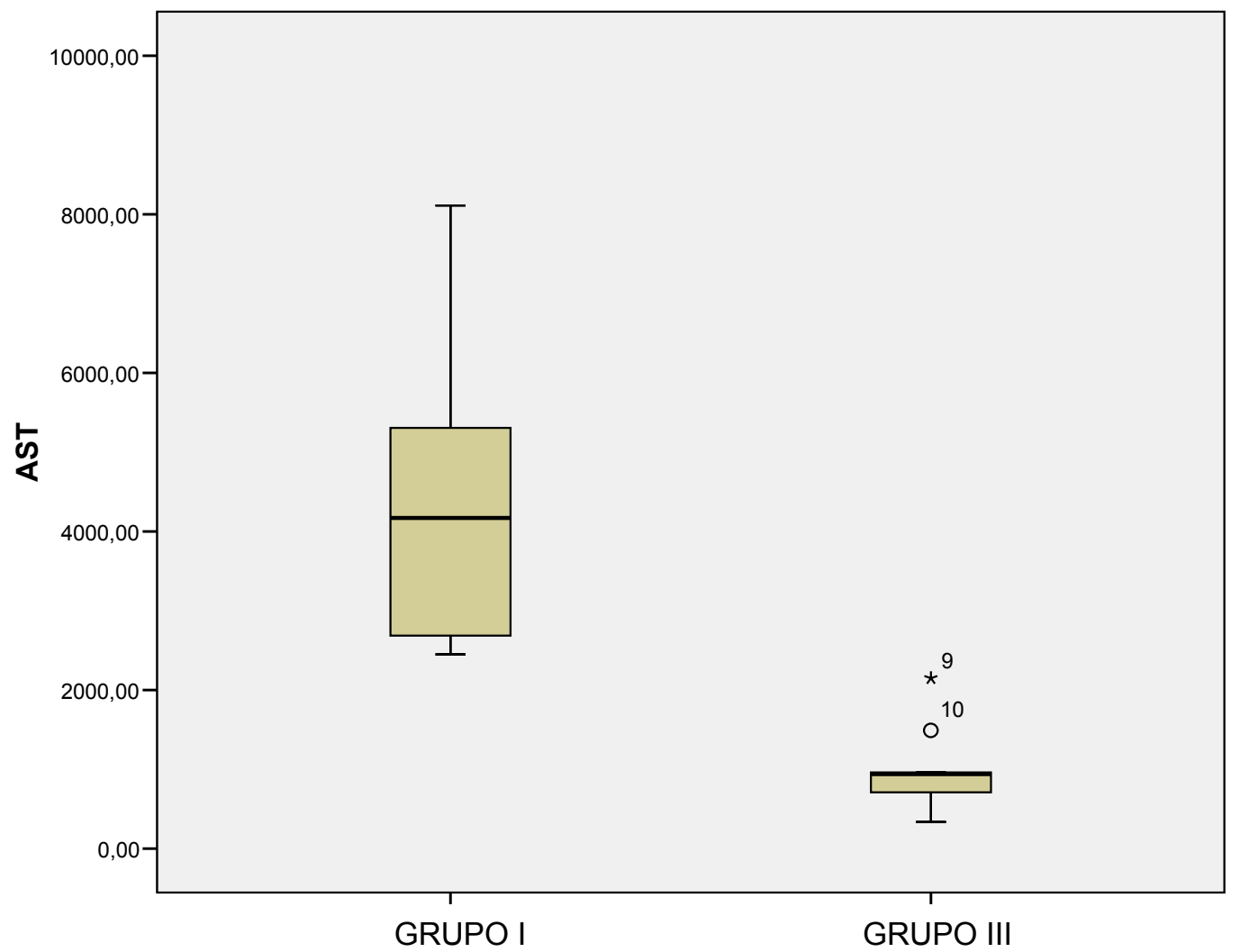

Figura 9: Comparação dos níveis séricos de AST (U/L) entre os grupos I (controle) e III (esteatose acentuada) $(p<0,001)$. Box-plot mostrando mediana, percentil de quartis e valores mínimo e máximo. 


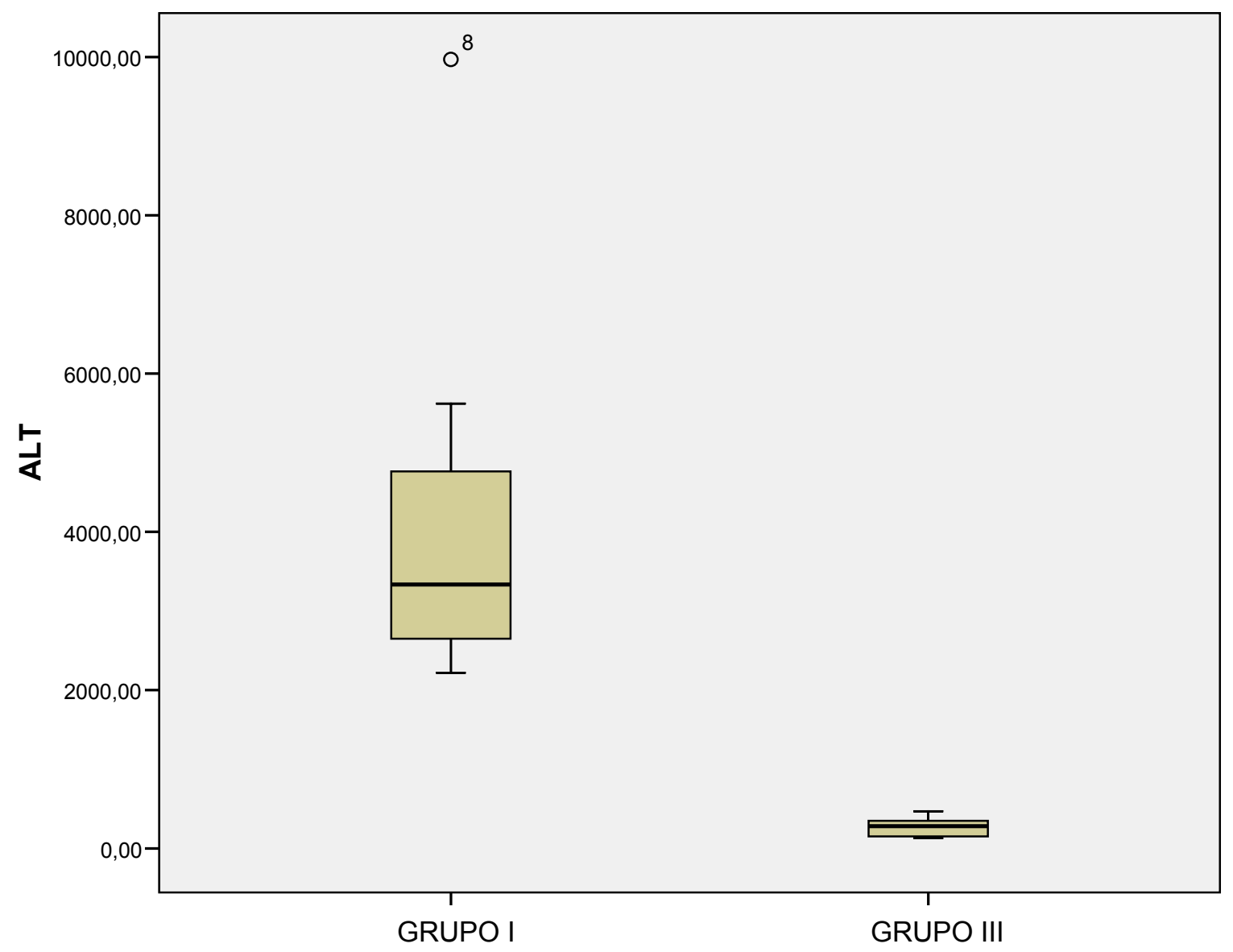

Figura 10: Comparação dos níveis séricos de $A L T$ (U/L) entre os grupos I (controle) e III (com esteatose) $(p<0,001)$. Box-plot mostrando mediana, percentil de quartis e valores mínimo e máximo. 


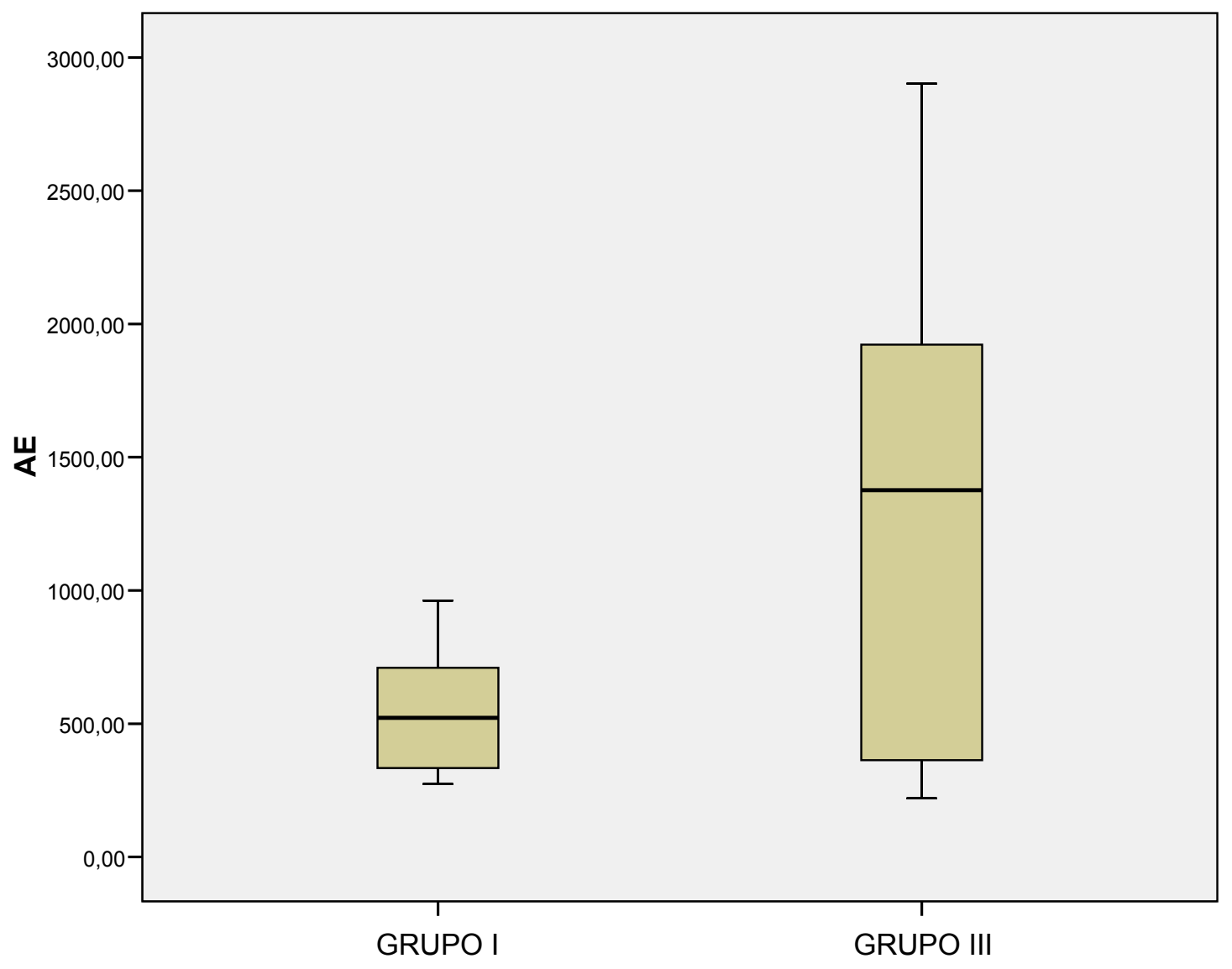

Figura 11: Comparação dos níveis de extravasamento de azul de Evans do pulmão (AE) ( $\mu \mathrm{g}$ de azul de Evans/g de tecido seco) entre os grupos I (controle) e III (esteatose acentuada) $(p=0,04)$. Box-plot mostrando mediana, percentil de quartis e valores mínimo e máximo. 


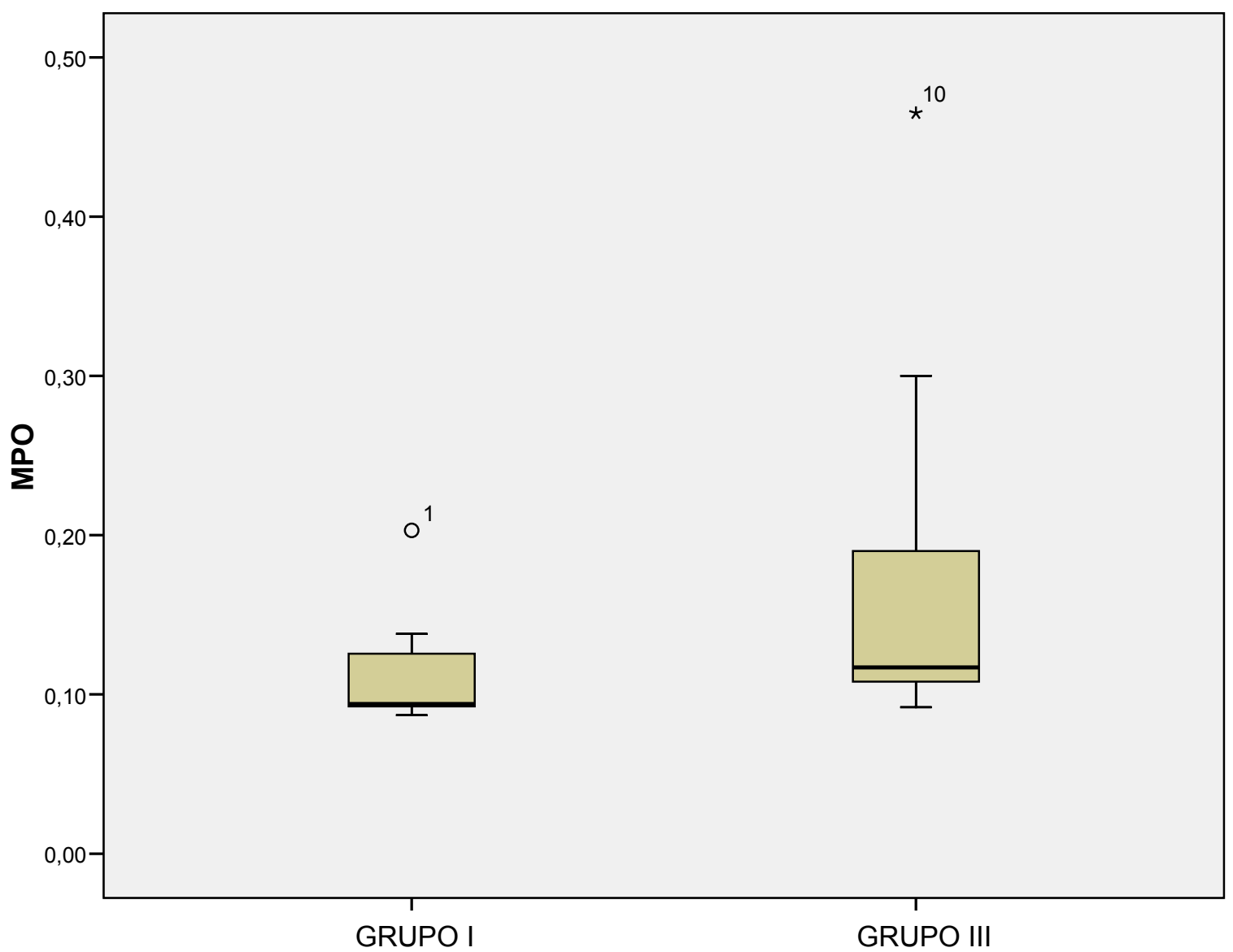

Figura 12: Comparação dos níveis de mieloperoxidase pulmonar (MPO) entre os grupos I (controle) e III (esteatose acentuada) $(p=0,05)$. Box-plot mostrando mediana, percentil de quartis e valores mínimo e máximo. 

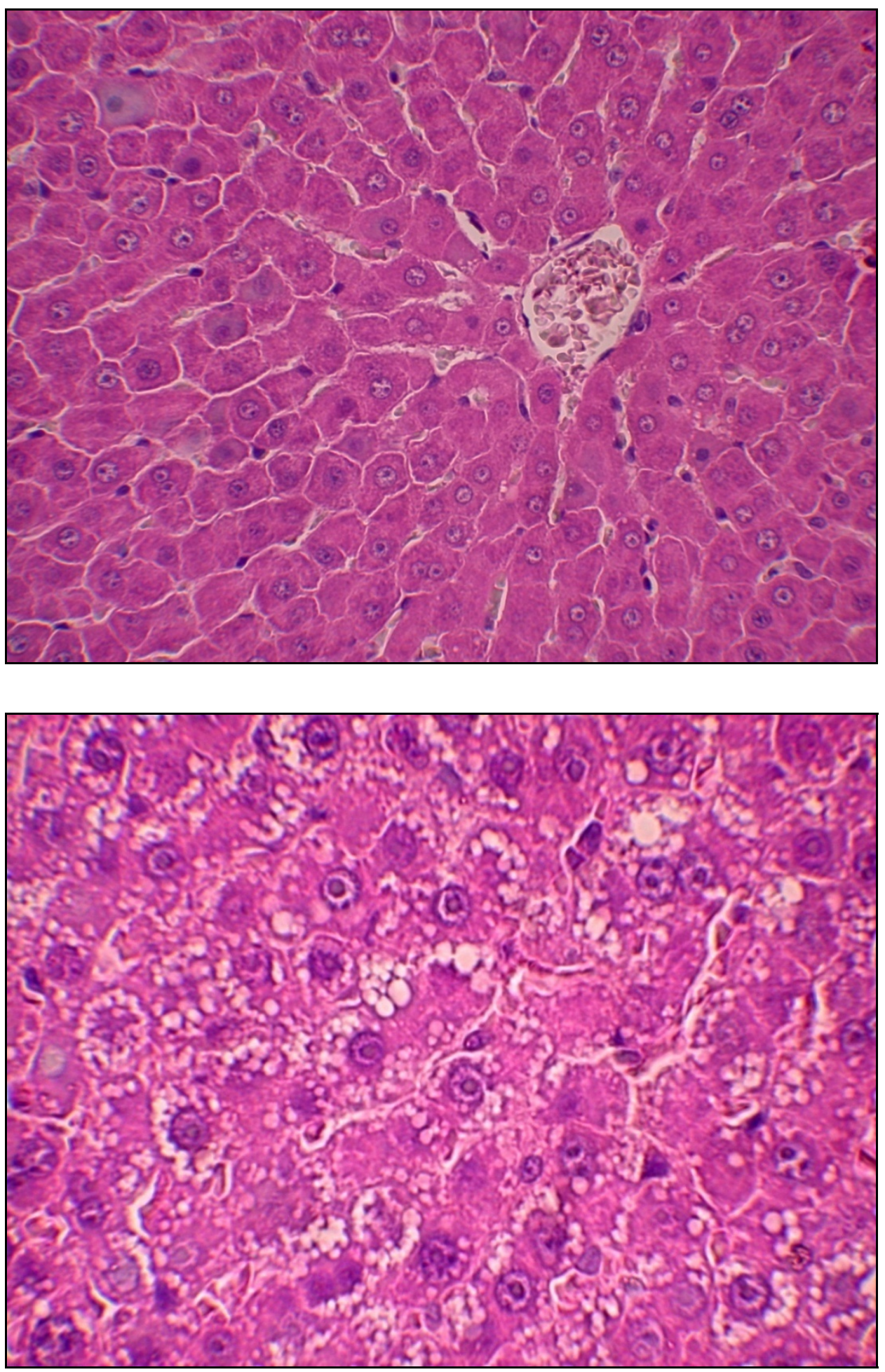

Figuras 13 e 14: Aspecto histológico representativo de fígado de animal do grupo I (controle) mostrando fígado normal comparado com fígado de animal do grupo III (dieta aproteica) mostrando esteatose intensa (HE 200x). 


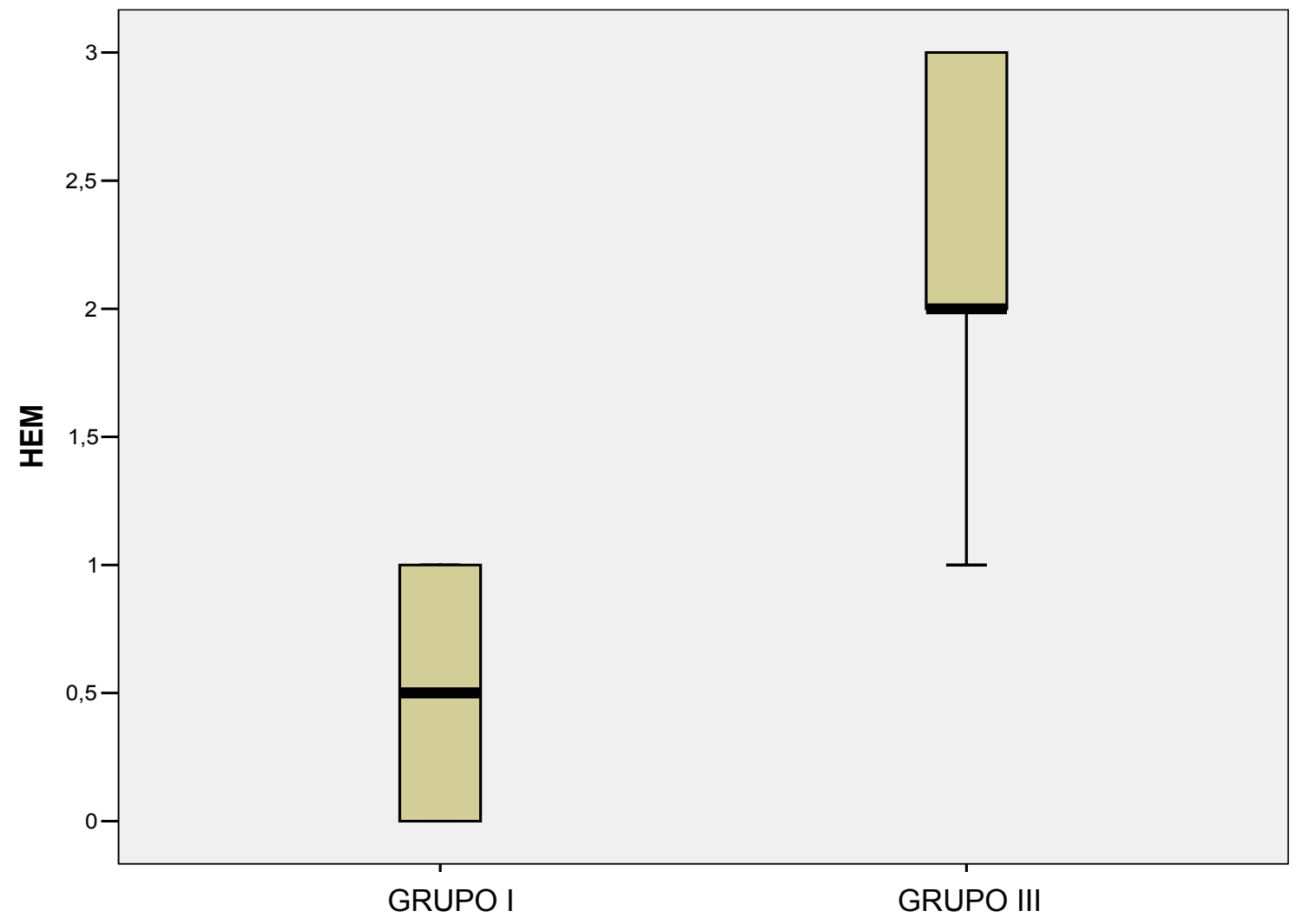

Figura 15: Comparação da hemorragia intraparenquimatosa histológica (HEM) da porção isquêmica do fígado entre os grupos I (controle) e III (esteatose acentuada) $(p=0,001)$. Box-plot mostrando mediana, percentil de quartis e valores mínimo e máximo. 


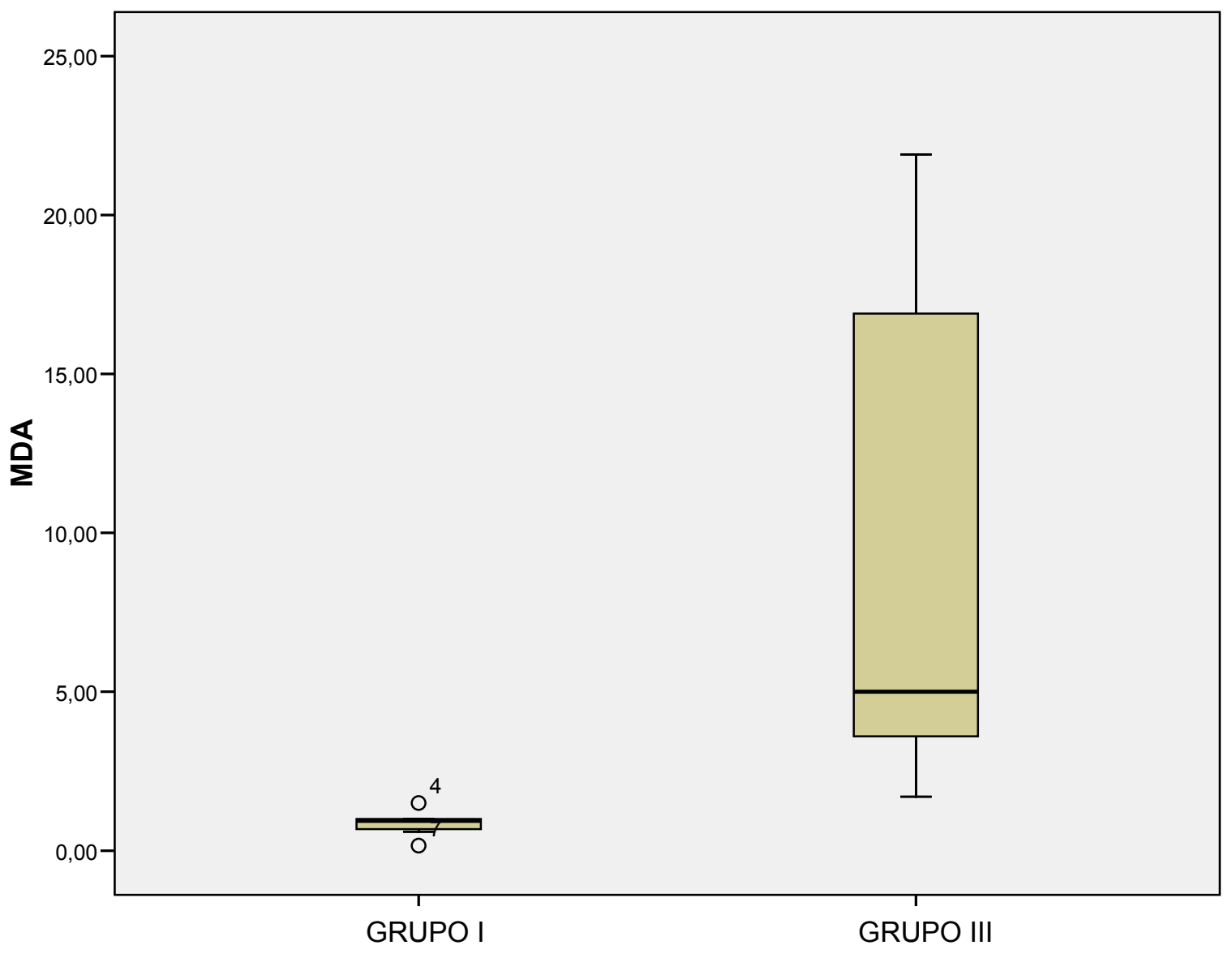

Figura 16: Comparação dos níveis de peroxidação lipídica utilizando o método MDA (nmol de malondialdeido equivalentes/mg de proteína) entre as porções não isquêmicas dos grupos I (controle) e III (esteatose acentuada) ( $p=0,008)$. Box-plot mostrando mediana, percentil de quartis e valores mínimo e máximo. 


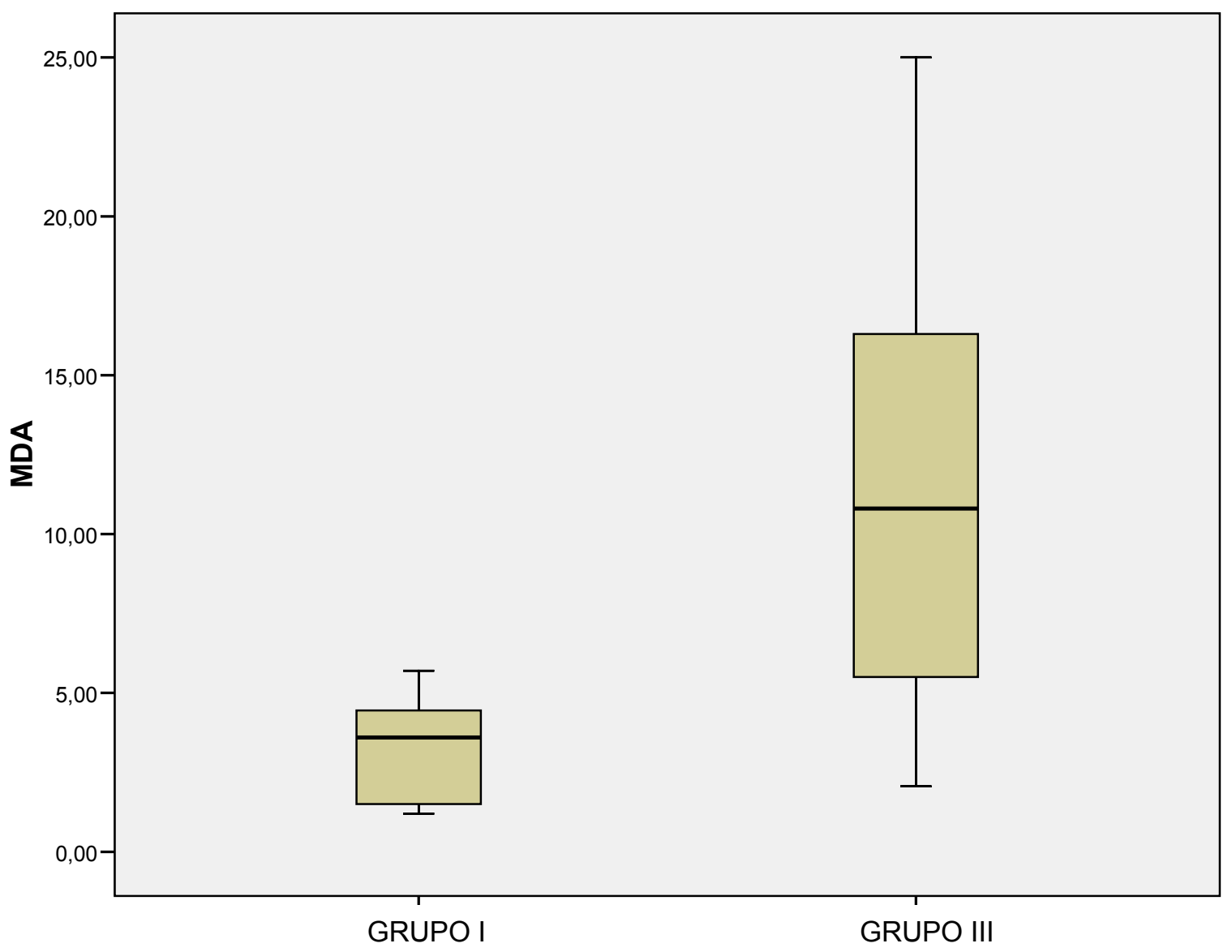

Figura 17: Comparação dos níveis de peroxidação lipídica utilizando o método MDA ( $\mathrm{nmol}$ de malondialdeido equivalentes/mg de proteína) entre as porções isquêmicas dos grupos I (controle) e III (esteatose acentuada) $(p=0,007)$. Box-plot mostrando mediana, percentil de quartis e valores mínimo e máximo. 


\subsection{Efeito da SNAC na lesão de isquemia e reperfusão em ratos com dieta balanceada}

A comparação entre os grupos I (ratos com dieta balanceada e tratados com solução salina) (controle) e II (ratos com dieta balanceada e tratados com SNAC) não mostrou diferença nas seguintes variáveis analisadas: AST $(p=0,72), A L T$ $(p=0,95)$, permeabilidade vascular pulmonar avaliada pela dosagem do corante azul de Evans $(p=0,15)$ e mieloperoxidase pulmonar $(p=0,88)$.

A histologia não mostrou diferença significativa entre os grupos I e II.

A comparação entre os grupos I e II na porção não isquêmica do fígado não mostrou diferença significativa em relação à função mitocondrial do tipo oxidativa $(R C R)(p=0,68)$, como também do tipo fosforilativa (ADP/O) $(p=0,53)$. Também não se encontrou diferença significativa no estresse oxidativo medido pelo MDA $(p=0,49)$.

A comparação entre os grupos I e II na porção isquêmica do fígado evidenciou: em relação à função mitocondrial, ausência de diferença significativa na função oxidativa $(R C R)(p=0,73)$, como também na função fosforilativa (ADP/O) $(p=0,77)$. Verificou-se uma tendência a menor estresse oxidativo medido pelo MDA no grupo II (com SNAC), mas sem diferença significativa $(p=0,07)$ (figura 18). 


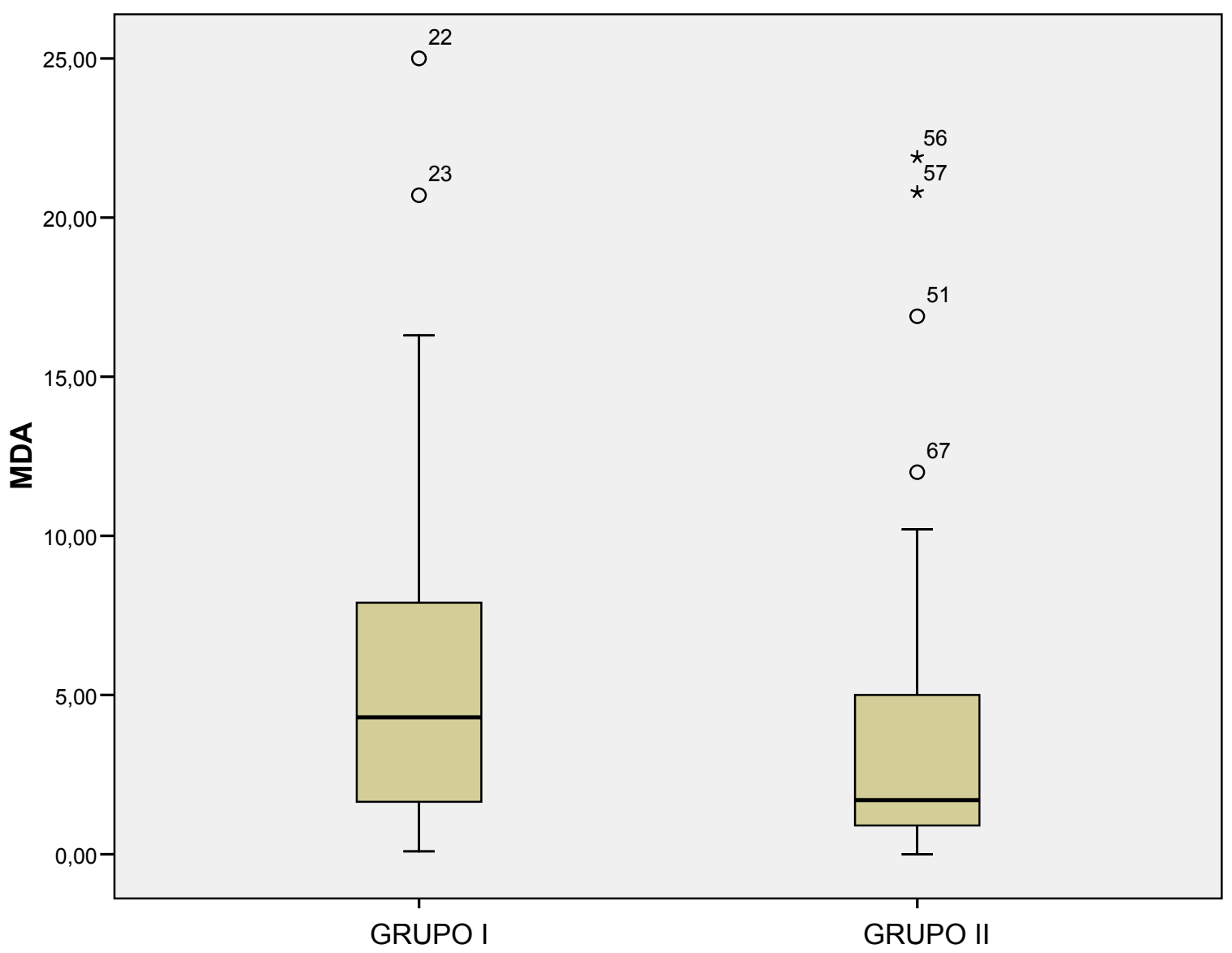

Figura 18: Comparação dos níveis de peroxidação lipídica utilizando o método MDA (nmol de malondialdeido equivalentes/mg de proteína) entre as porções isquêmicas dos grupos I (controle) e II (SNAC) $(p=0,07)$. Box-plot mostrando mediana, percentil de quartis e valores mínimo e máximo. 


\subsection{Efeito da SNAC na lesão de isquemia e reperfusão em ratos com esteatose acentuada}

A comparação entre os grupos III (ratos com dieta aproteica e tratados com solução salina) e IV (ratos com dieta aproteica e tratados com SNAC) não mostrou diferença significativa nas seguintes variáveis avaliadas: AST $(p=0,64)$, ALT $(p=0,63)$, permeabilidade vascular pulmonar avaliada pela dosagem do corante azul de Evans $(p=0,92)$ e mieloperoxidase pulmonar $(p=0,39)$.

A histologia mostrou redução da hemorragia intraparenquimatosa na porção isquêmica do fígado no grupo tratado com SNAC (grupo IV) quando comparado com o mesmo grupo que recebeu solução salina (grupo III) $(p=0,02)$ (figuras 19, 20 e 21).

A comparação entre os grupos III e IV na porção não isquêmica do fígado evidenciou: em relação à função mitocondrial uma tendência de melhora na função oxidativa (RCR) no grupo IV (esteatótico com SNAC) mas sem diferença significativa $(p=0,1)$ (figura 22), e melhora significativa na função fosforilativa (ADP/O) neste mesmo grupo $(p=0,005)$ (figura 23$)$. Todavia não evidenciou diferença significativa no estresse oxidativo medido pelo $\operatorname{MDA}(p=0,178)$.

A comparação entre os grupos III e IV na porção isquêmica do fígado evidenciou: em relação a função mitocondrial melhora significativa tanto na função oxidativa $(R C R)(p=0,01)$ (figura 24$)$, como também na função fosforilativa (ADP/O) $(p=0,03)$ (figura 25). Mostrou também tendência a menor estresse oxidativo medido pelo MDA no grupo IV (esteatótico com SNAC) mas sem diferença significativa $(p=0,07)$ (figura 26). 


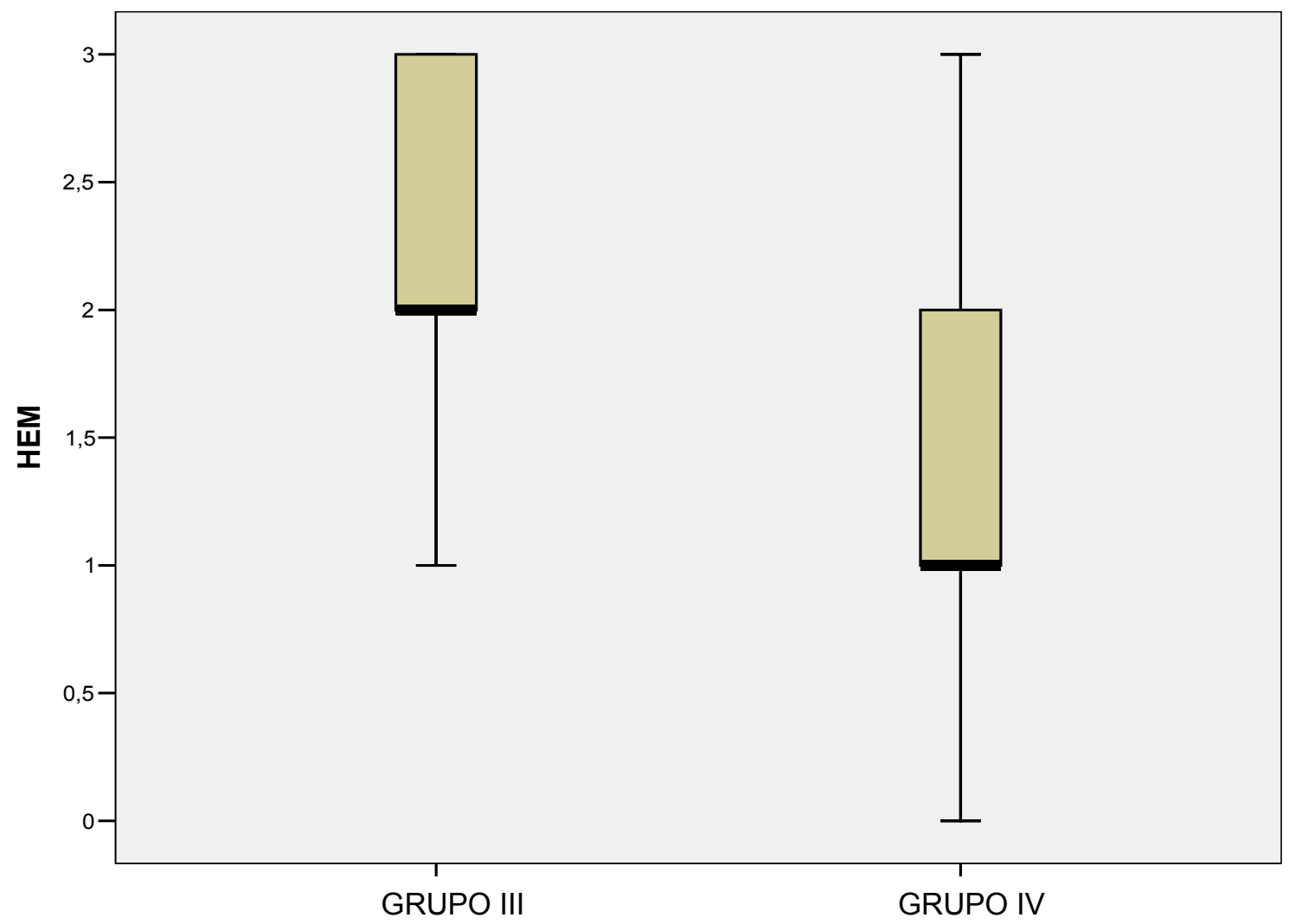

Figura 19: Comparação da intensidade de hemorragia intraparenquimatosa avaliada pelo escore histológico da porção isquêmica entre os grupos III (esteatose acentuada) e IV (esteatose acentuada e SNAC) $(p=0,02)$. Box-plot mostrando mediana, percentil de quartis e valores mínimo e máximo. 

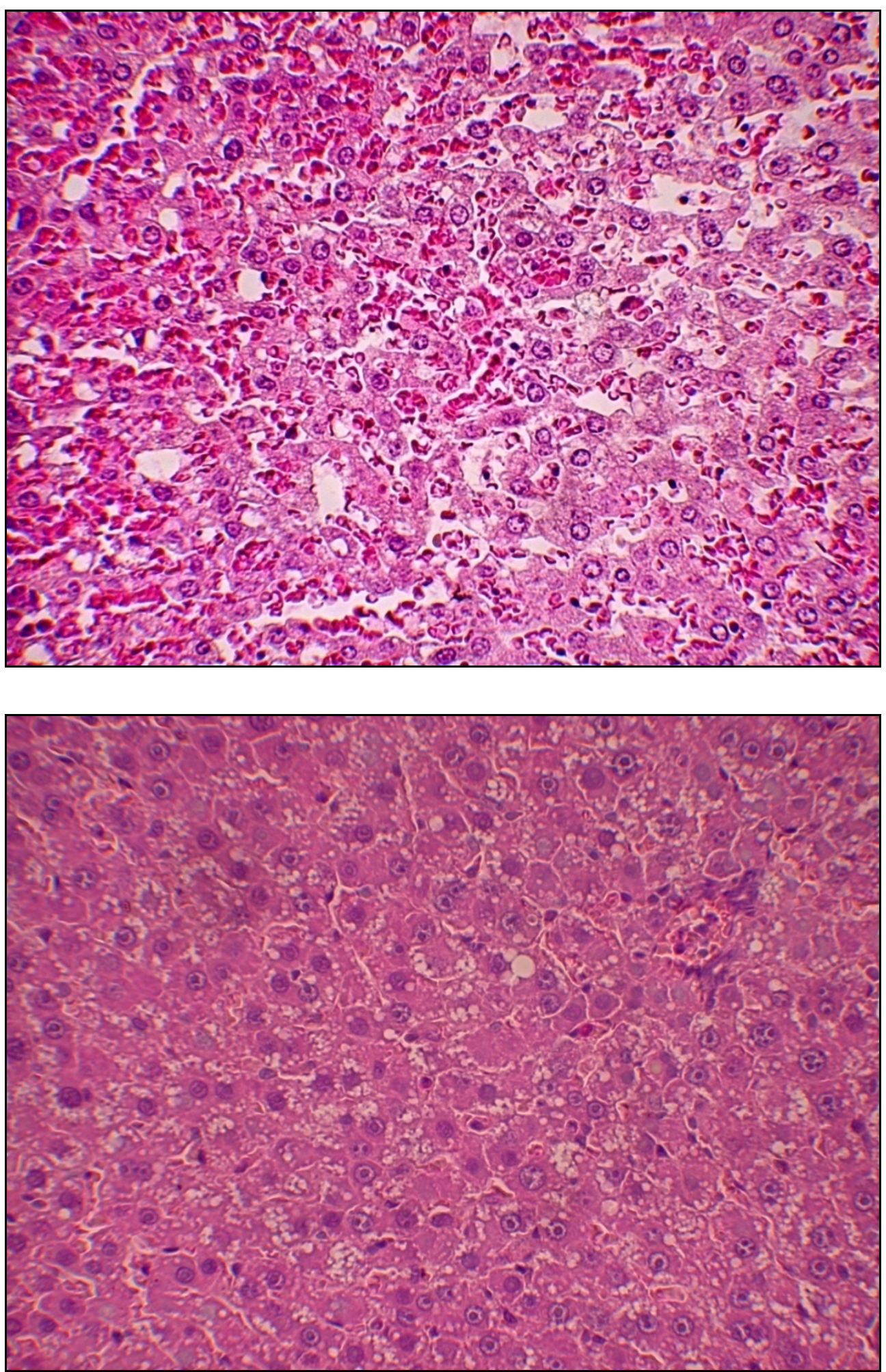

Figuras 20 e 21: Aspecto histológico representativo do lobo hepático isquêmico de animal do grupo III (dieta aproteica e solução salina) mostrando esteatose e hemorragia intensas comparado com o do lobo hepático isquêmico de animal do grupo IV (dieta aproteica e SNAC) mostrando esteatose moderada sem hemorragia (HE 200x). 


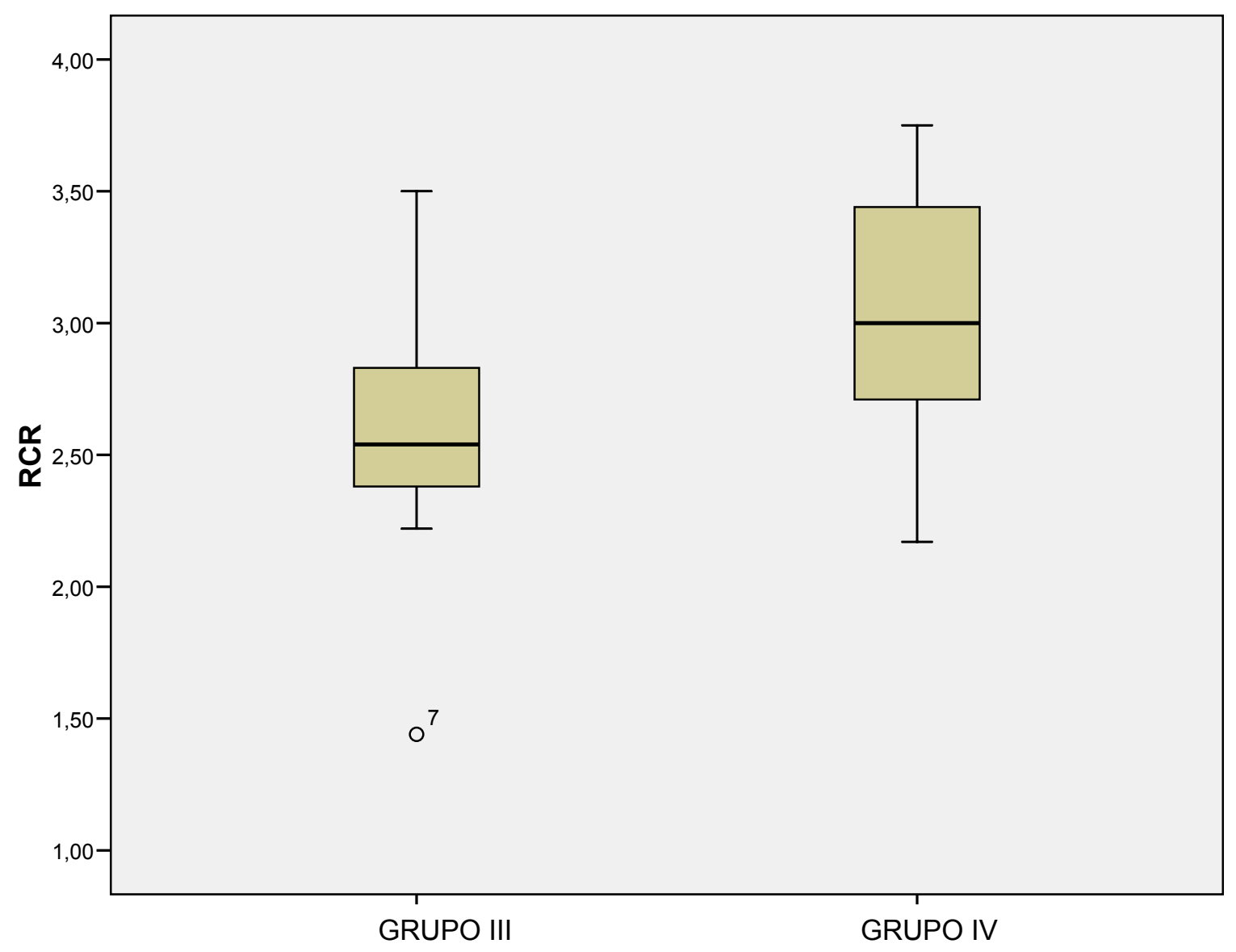

Figura 22: Comparação dos valores da razão do controle respiratório (RCR) entre as porções não isquêmicas do fígado dos grupos III (esteatose acentuada) e IV (esteatose acentuada e SNAC) $(p=0,1)$. Box-plot mostrando mediana, percentil de quartis e valores mínimo e máximo. 


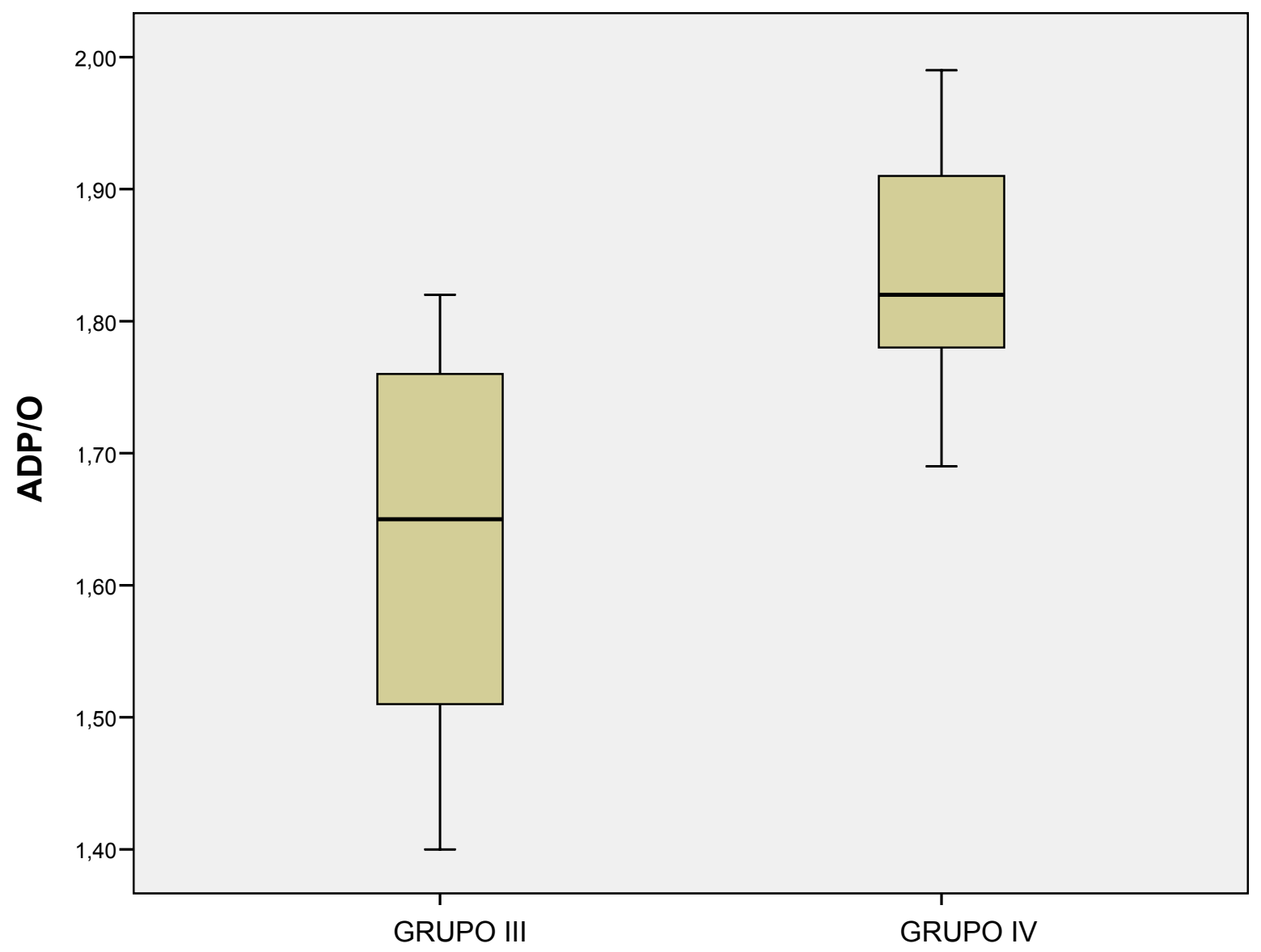

Figura 23: Comparação dos valores da relação $A D P / O$ entre as porções não isquêmicas do fígado dos grupos III (esteatose acentuada) e IV (esteatose acentuada e SNAC) $(p=0,05)$. Box-plot mostrando mediana, percentil de quartis e valores mínimo e máximo. 


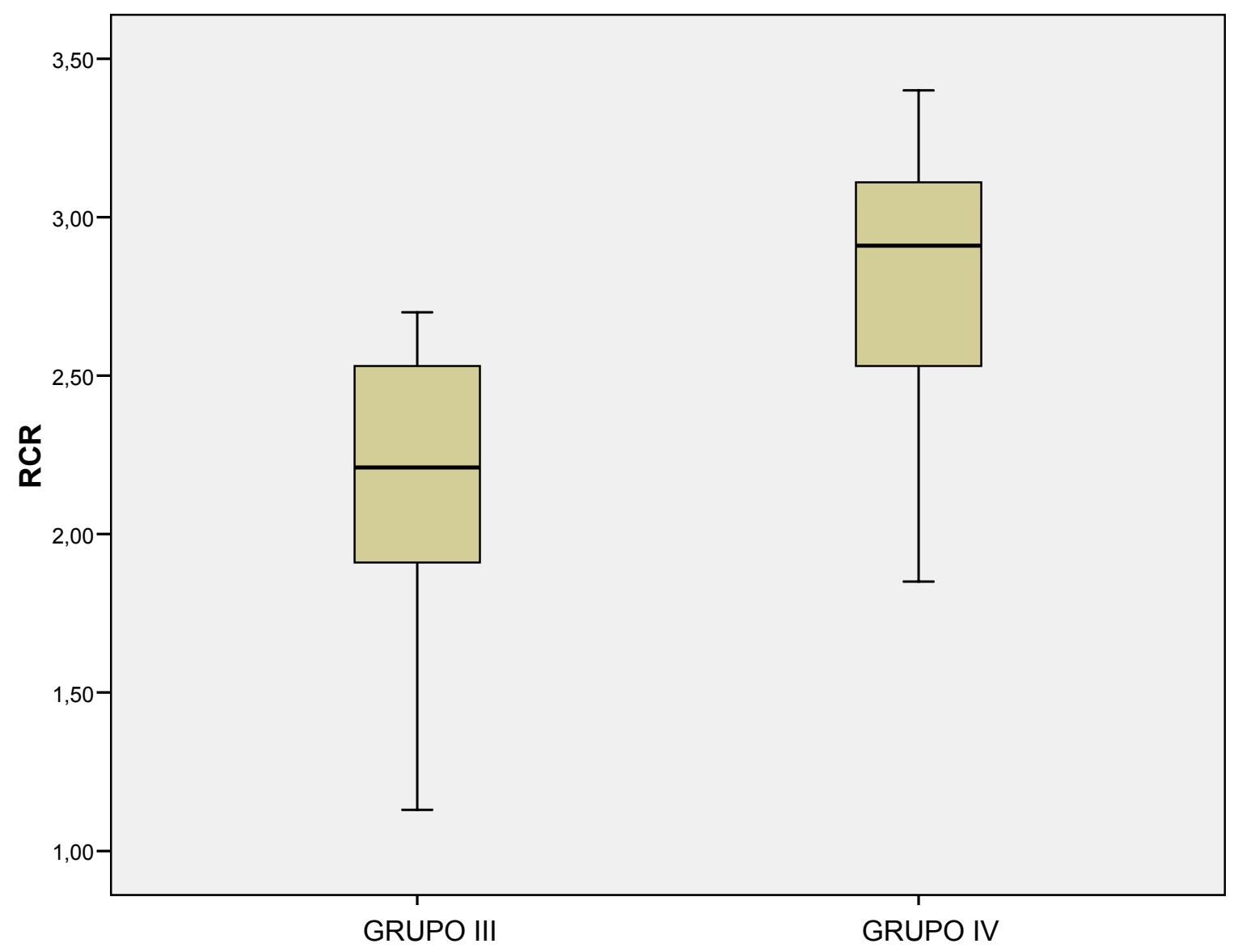

Figura 24: Comparação dos valores da razão do controle respiratório (RCR) entre as porções isquêmicas do fígado dos grupos III (esteatose acentuada) e IV (esteatose acentuada e SNAC) $(p=0,01)$. Box-plot mostrando mediana, percentil de quartis e valores mínimo e máximo. 


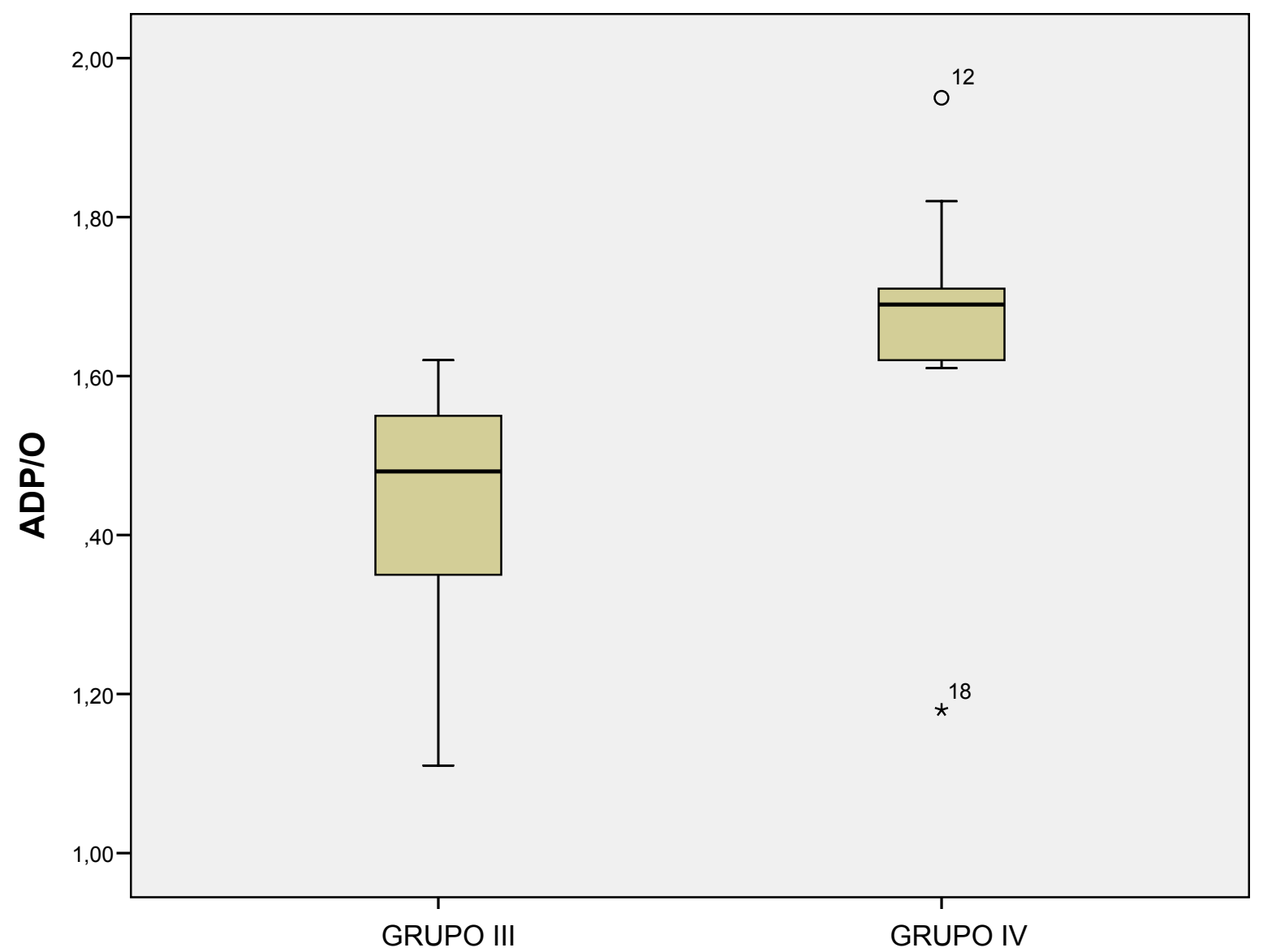

Figura 25: Comparação dos valores da relação ADP/O entre as porções isquêmicas do fígado dos grupos III (esteatose acentuada) e IV (esteatose acentuada e SNAC) $(p=0,03)$. Box-plot mostrando mediana, percentil de quartis e valores mínimo e máximo. 


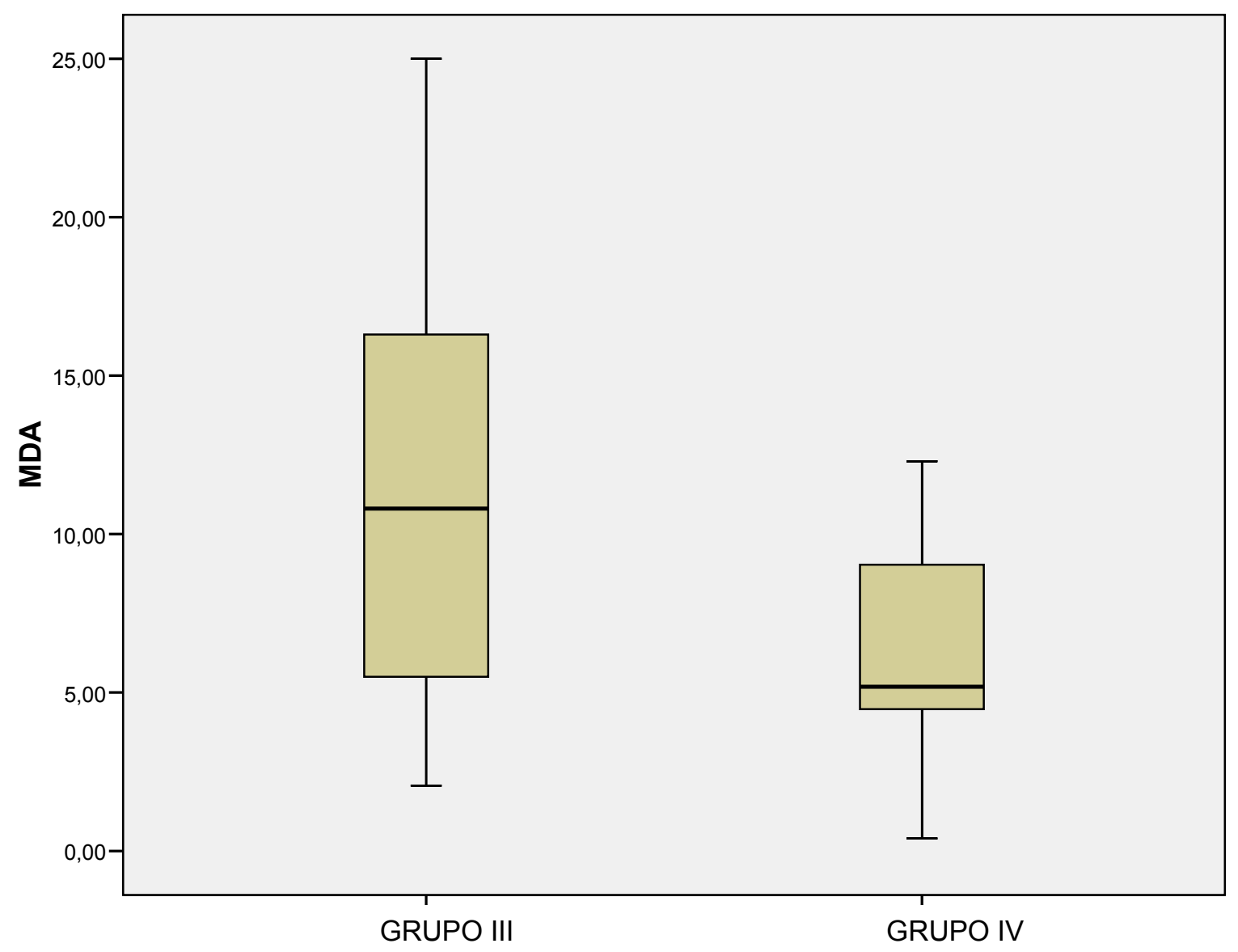

Figura 26: Comparação dos níveis de peroxidação lipídica utilizando o método MDA ( $\mathrm{nmol}$ de malondialdeido equivalentes/mg de proteína) entre as porções isquêmicas do fígado dos grupos III (esteatose acentuada) e IV (esteatose acentuada e SNAC) $(p=0,07)$. Box-plot mostrando mediana, percentil de quartis e valores mínimo e máximo. 


\subsection{Efeito da isquemia e reperfusão hepática parcial na porção não isquêmica do fígado}

A comparação entre as porções isquêmicas e não isquêmicas de cada grupo evidenciou:

a) em relação à função mitocondrial:

Nos grupos com dieta balanceada (grupos I e II) a porção não isquêmica do fígado apresentou melhor função mitocondrial quando comparada com a porção isquêmica dos mesmos animais, avaliada tanto pelo RCR (função oxidativa) ( $p=0,002$ e $p=0,007$ ) (figura 27) quanto pelo ADP/O (função fosforilativa) $(p=0,024$ e $p=0,018)$ (figura 28).

Nos grupos com dieta aproteica (esteatose acentuada) (grupos III e IV) não houve diferença entre as porções não isquêmicas e isquêmicas do fígado dos mesmos animais na avaliação pelo RCR (função oxidativa) ( $p=0,106$ e $p=0,325)$ (figura 27). A porção não isquêmica apresentou melhor função fosforilativa (ADP/O) quando comparada com a porção isquêmica dos mesmos animais $(p=0,017$ e 0,042) (figura 28).

b) Em relação ao estresse oxidativo:

Nos grupos com dieta balanceada (controle da esteatose) (grupos I e II) a porção não isquêmica do fígado apresentou menor estresse oxidativo medido pelo MDA quando comparada com a 
porção isquêmica dos mesmos animais no grupo I $(p=0,003)$ e uma tendência no grupo II $(p=0,079)$ (figura 29$)$.

Nos grupos com dieta aproteica (esteatose acentuada) (grupos III e IV) não houve diferença entre as porções não isquêmicas e isquêmicas do fígado dos mesmos animais no estresse oxidativo avaliado pelo método do MDA ( $p=0,53$ e 0,58) (figura 29). 


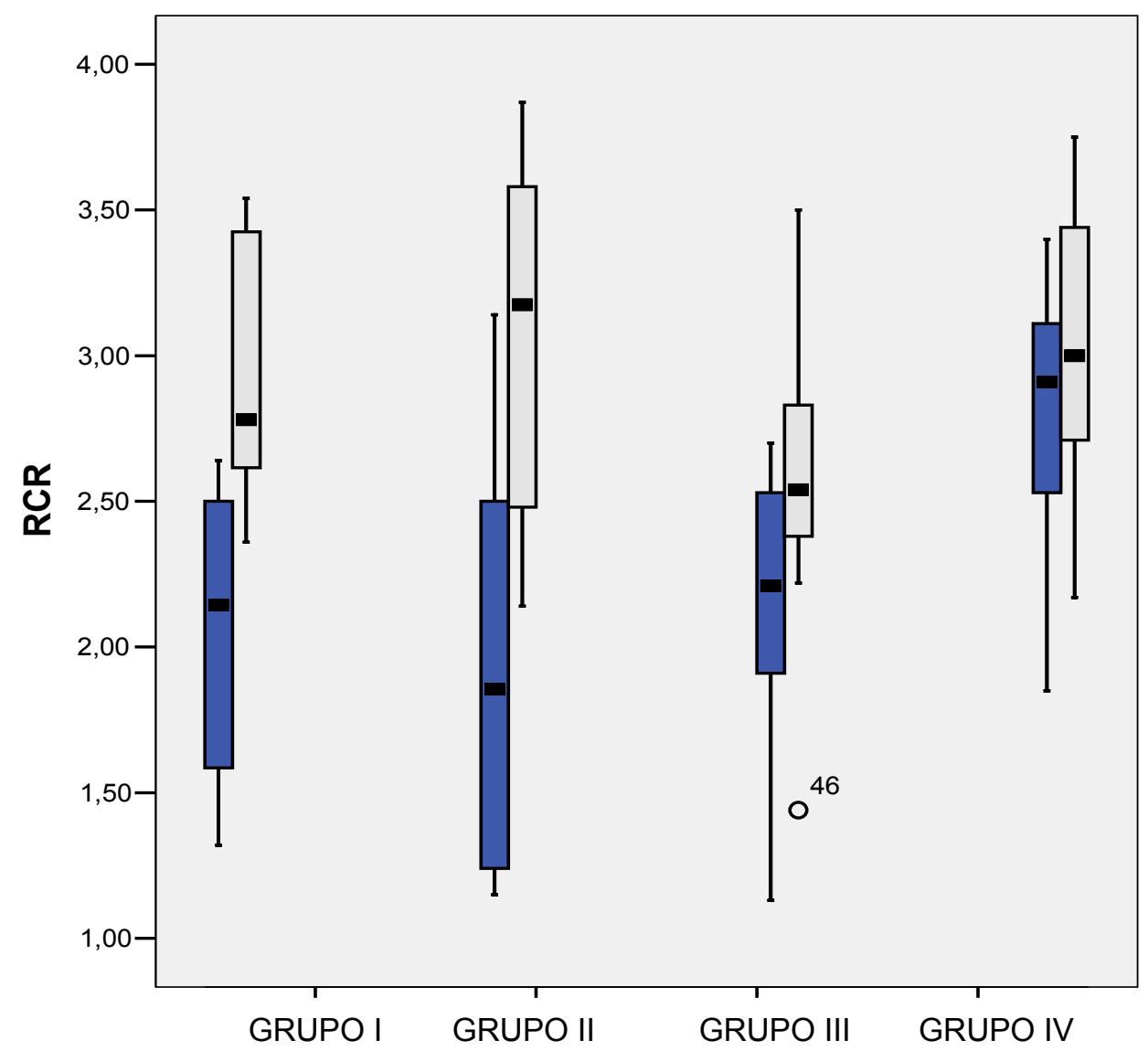

Isquêmico

Não isquêmico

Figura 27: Comparação dos valores da razão do controle respiratório (RCR) entre as porções isquêmicas e não isquêmicas dos grupos I (dieta balanceada) $(p=0,002)$, II (dieta balanceada e SNAC) $(p=0,007)$, III (esteatose acentuada) $(p=0,106)$ e IV (esteatose acentuada e SNAC) $(p=0,325)$. Box-plot mostrando mediana, percentil de quartis e valores mínimo e máximo. 


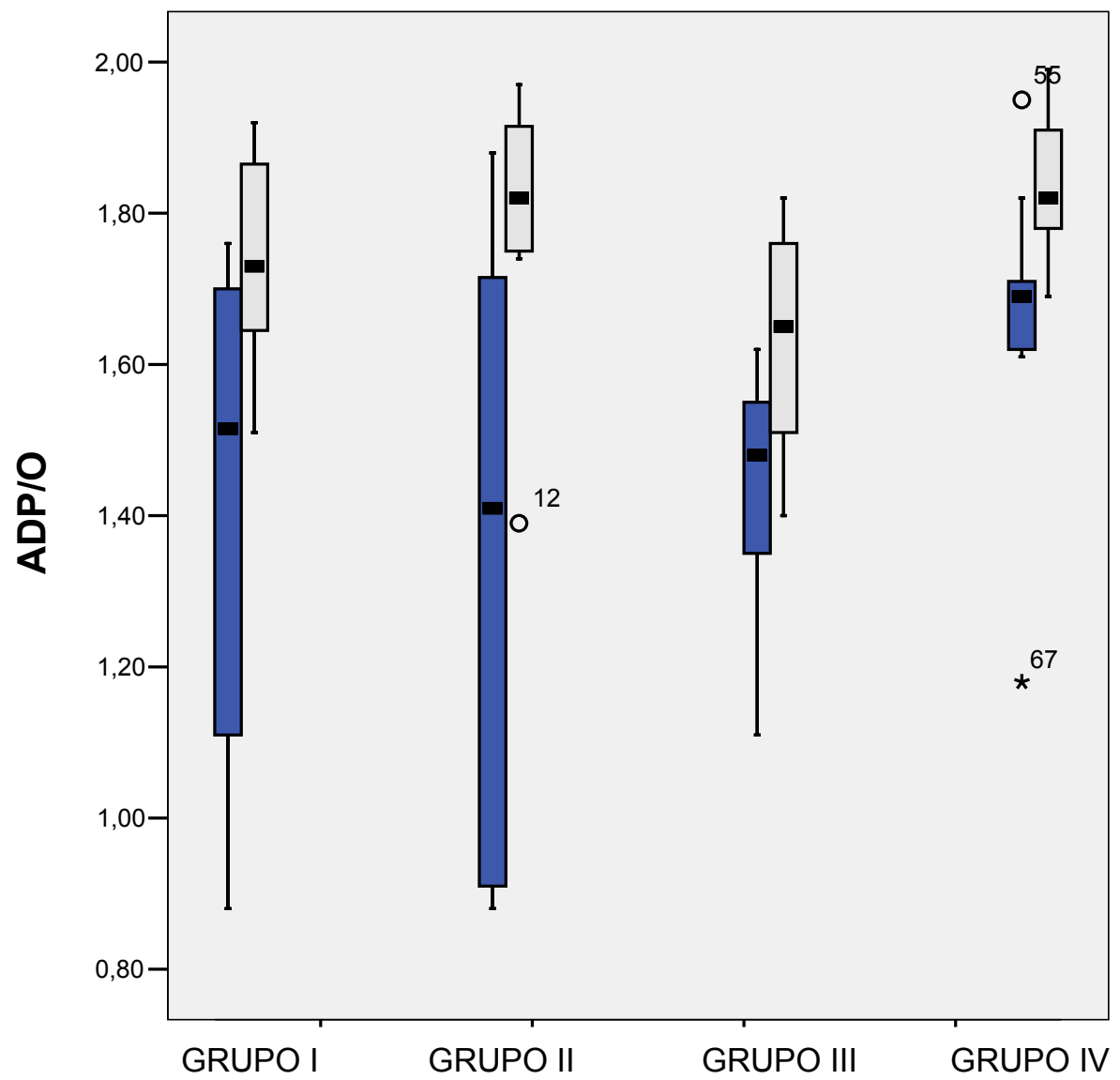

Isquêmico

Não isquêmico

Figura 28: Comparação dos valores da relação ADP/O entre as porções isquêmicas e não isquêmicas dos grupos I (dieta balanceada) $(p=0,024)$, II (dieta balanceada e SNAC) $(p=0,018)$, III (esteatose acentuada) $(p=0,017)$ e IV (esteatose acentuada e SNAC) $(p=0,042)$. Box-plot mostrando mediana, percentil de quartis e valores mínimo e máximo. 


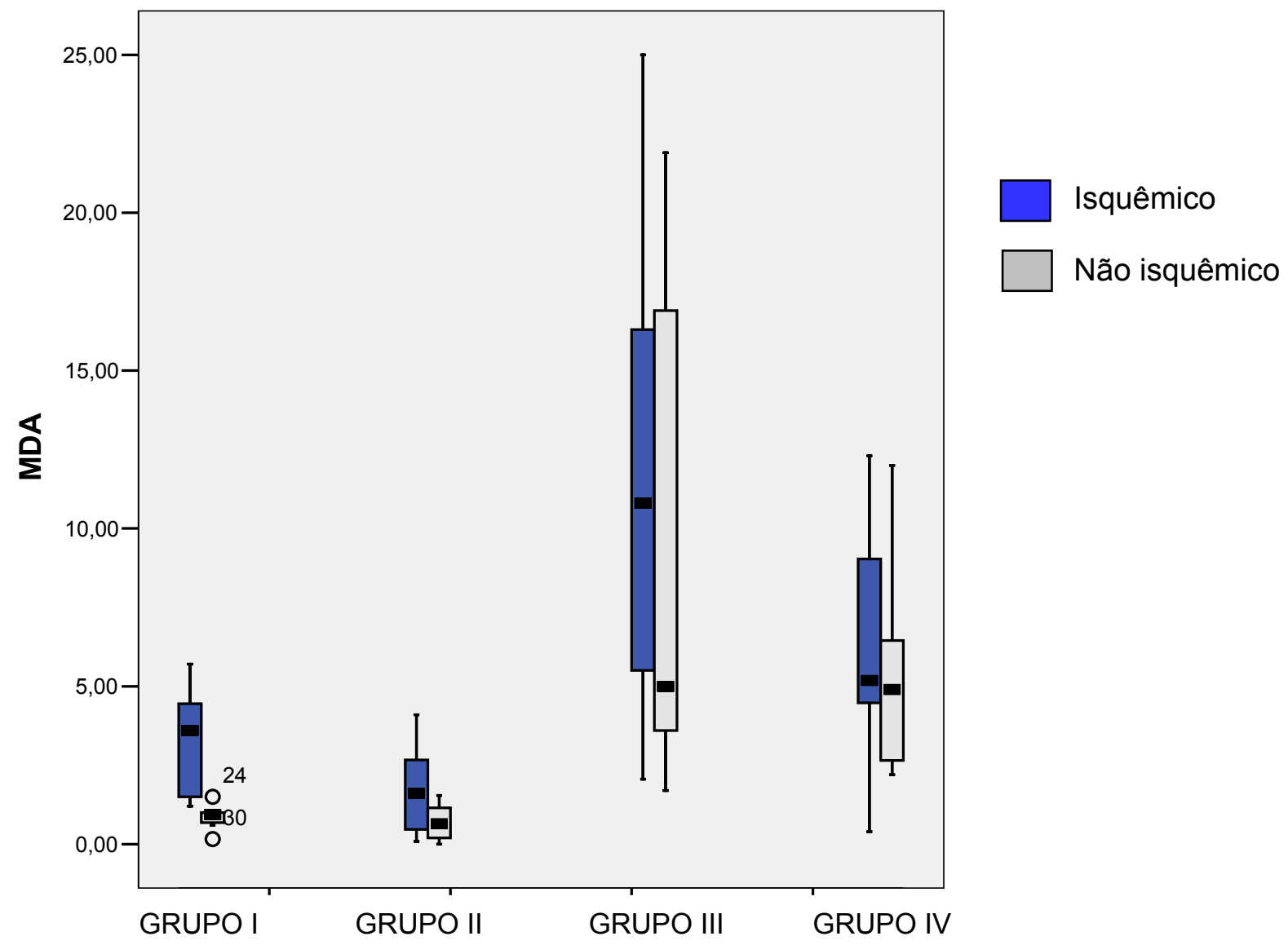

Figura 29: Comparação dos níveis de peroxidação lipídica utilizando o método MDA ( $\mathrm{nmol}$ de malondialdeido equivalentes/mg de proteína) entre as porções isquêmicas e não isquêmicas dos grupos I (dieta balanceada) $(p=0,003)$, II (dieta balanceada e SNAC) $(p=0,079)$, III (esteatose acentuada) $(p=0,53)$ e IV (esteatose acentuada e SNAC) $(p=0,58)$. Box-plot mostrando mediana, percentil de quartis e valores mínimo e máximo. 
5 - DISCUSSÃO 


\section{DISCUSSÃO}

A esteatose tem se mostrado importante fator de risco em todas intervenções sobre o fígado que incluam isquemia e reperfusão hepáticas. ${ }^{27,62}$ Vários modelos experimentais tem sido utilizados para a avaliação dos efeitos deletérios da esteatose hepática. A indução de esteatose hepática por dieta deficiente em colina e metionina representa o modelo mais utilizado na literatura. ${ }^{36,38,63}$ Outros modelos utilizam animais modificados geneticamente, promovendo obesidade, como ratos Zucker, ${ }^{23,28}$ e também algumas drogas hepatotóxicas tem sido testadas. ${ }^{34}$ No presente trabalho optou-se por utilizar dieta aproteica, provocando desnutrição proteica, que induz uma intensa esteatose hepática em período curto de tempo e sem provocar outras alterações histológicas relevantes no fígado. Este modelo já havia sido utilizado anteriormente em nosso meio em estudos de pancreatite aguda experimental e estudos de avaliação da composição enzimática do pâncreas. ${ }^{47,48}$ Sua grande vantagem é a indução de esteatose num período mais curto de tempo.

A esteatose hepática por baixa ingesta proteica já foi observada em crianças com desnutrição. ${ }^{64} \mathrm{O}$ mecanismo pelo qual a desnutrição proteica provoca acúmulo de gordura no fígado ainda é controverso. Um dos mecanismos fisiopatológicos mais aceitos é o prejuízo da produção de VLDL apolipoproteína B-100 que é responsável pela mobilização hepática de triacilglicerol e também de colesterol, ésteres de colesterol e fosfolípides. ${ }^{65,66}$ Contudo, esta hipótese ainda não foi totalmente comprovada e existem outras hipóteses para explicar a esteatose nestes casos, tais como: aumento da produção hepática de ácidos graxos, prejuízo na $\beta$-oxidação de ácidos graxos tanto pelos hepatócitos como por todo o organismo e aumento da

entrada de ácidos graxos no fígado secundário ao aumento da lipólise. ${ }^{67,68} \mathrm{De}$ 
qualquer forma, a esteatose está intimamente relacionada com a desnutrição proteica, de tal modo que o modelo utilizado no presente trabalho produziu esteatose pronunciada em curto período de tempo, mimetizando esteatose encontrada na prática clínica.

Os efeitos deletérios da esteatose hepática foram confirmados por Teramoto et $\mathrm{al}^{21}$ que em estudo experimental, avaliando transplante hepático em ratos com esteatose induzida por dieta deficiente em colina e metionina, encontraram alterações microcirculatórias no grupo esteatótico, com sinusóides mais estreitos e irregulares, e adesão de células inflamatórias à parede sinusoidal. Outros autores mostraram alterações semelhantes em trabalhos experimentais. ${ }^{28,29,31}$ Em pesquisa clínica, Belghiti et $a{ }^{26}$ estudando 478 pacientes com ressecção hepática eletiva incluindo 37 com esteatose, verificaram ser esta um fator de risco independente para complicações pós operatórias.

Um dos mecanismos de ação pelo qual a esteatose causa dano ao fígado é a disfunção mitocondrial. ${ }^{15,34}$ Natarajan et al ${ }^{69}$ estudaram esteatose microvesicular induzida por valproato de sódio em ratos. Encontraram, no grupo esteatótico, aumento do estresse oxidativo com conseqüente dano tecidual hepático, devido a maior oxidação lipídica por microssomos e peroxissomos, e prejuízo na $\beta$ oxidação mitocondrial. Em nosso meio, Oliveira et al $^{70}$ estudaram em ratos esteatose induzida por dieta deficiente em colina, e encontraram aumento do estresse oxidativo e disfunção mitocondrial, com maior consumo de oxigênio na fase 4 (S4) e diminuição da razão de controle respiratório (RCR) no grupo esteatótico.

No presente trabalho, observou-se que a isquemia e reperfusão hepáticas provocaram, no grupo com esteatose acentuada, significativo aumento do estresse oxidativo (figuras 16 e 17) e também aumento de inflamação à distância avaliada 
pelo azul de Evans e mieloperoxidase pulmonares (figuras 11 e 12) quando comparado ao grupo controle. O exame histológico confirmou estes achados evidenciando piora no grupo esteatótico com maior hemorragia intraparenquimatosa (figuras 13, 14 e 15).

Parodoxalmente, o grupo não esteatótico apresentou valores de transaminases maiores que o grupo esteatótico (figuras 9 e 10). Este fato pode ser explicado pela indução da esteatose com a dieta aproteica por um período de 21 dias, que produz desnutrição, com diminuição do peso corpóreo e hepático dos ratos em questão. Outros modelos experimentais de esteatose, como dieta deficiente em colina, dieta deficiente em metionina e colina, dieta hiperlipídica ou modificação genética, não promovem desnutrição grave, e utilizam ALT e AST séricas como parâmetro de gravidade da lesão hepática. Com a desnutrição, ocorre uma diminuição da massa citoplasmática hepatocitária e da massa hepática total antes do experimento (I/R), fazendo com que a lesão mesmo de um grande número de hepatócitos provoque um menor aumento sérico de transaminases (AST e ALT). Este achado sugere que a análise de ALT e AST séricos, neste modelo experimental de esteatose, não é um bom parâmetro para a avaliação da gravidade de lesão hepática quando se utiliza como controle animais com dieta balanceada.

O estudo comparativo das porções isquêmicas e não isquêmicas de cada grupo revelou: melhor função mitocondrial fosforilativa na porção não isquêmica de todos os grupos, contudo uma melhor função mitocondrial oxidativa apenas na porção não isquêmica dos grupos não esteatóticos. A I/R também produziu menor estresse oxidativo nas porções não isquêmicas dos grupos não esteatóticos (grupo I e grupo II) (figuras 27, 28 e 29). Em suma, os grupos esteatóticos apresentaram após isquemia e reperfusão respostas semelhantes em relação à função 
mitocondrial e ao estresse oxidativo nas porções isquêmicas e não isquêmicas do fígado. Este achado demonstra uma pior evolução da porção não isquêmica nos grupos esteatóticos após a isquemia e reperfusão, e reforça o fato de que a esteatose agrava a lesão pós I/R hepática parcial, não apenas de maneira local, mas também à distância.

No presente trabalho, pelo método utilizado, foi avaliado o efeito da esteatose acentuada sobre a lesão de I/R. Sabe-se que em sua fase final, na lesão de isquemia e reperfusão, os neutrófilos ativados vão liberar espécies reativas de oxigênio e proteases que são responsáveis pela indução do estresse oxidativo. ${ }^{24}$ Grande número de agentes antioxidantes já se mostraram benéficos no tratamento da lesão de isquemia e reperfusão hepáticas em trabalhos clínicos e sobretudo em trabalhos experimentais. ${ }^{24} \mathrm{~A} \mathrm{~N}$-acetilcisteína, precursora da glutationa, coloca-se entre os antioxidantes testados que mostraram benefício na $\mathrm{I} / \mathrm{R}$ hepática. Glantzounis et al $^{71}$ avaliaram o efeito da N-acetilcisteína em I/R em fígado de coelhos e encontraram diminuição de ALT e melhora na microcirculação hepática no grupo tratado.

Alguns agentes antioxidantes também foram testados experimentalmente em I/R em fígados esteatóticos. Soltys et $\mathrm{al}^{37}$ estudaram o efeito do tocoferol em I/R em ratos obesos (Zucker - Ob) e encontraram melhora da sobrevida no grupo tratado. Nakano et $\mathrm{al}^{36}$ estudando I/R em ratos com esteatose, induzida por dieta deficiente em colina e metionina, encontraram melhora das lesões da microcirculação hepática avaliada por microscopia eletrônica no grupo tratado com N-acetilcisteína.

A SNAC, que foi a droga testada no presente estudo, além de fornecer a Nacetilcisteína já mencionada, fornece também óxido nítrico (NO). O NO, de maneira fisiológica, regula a perfusão hepática, previne adesão plaquetária, trombose e 
acúmulo de células polimorfonucleares. Contudo em excesso pode produzir peroxinitrito, com produção de radicais livres e aumento da lesão por estresse oxidativo. ${ }^{24}$ A literatura sobre o efeito do NO na l/R hepática é ainda controversa. Alguns estudos sugerem efeito deletério na função hepática, ${ }^{72}$ outros efeito benéfico $^{73}$ e outros ainda ausência de alterações. ${ }^{74}$

Especificamente a SNAC, que é um thiol doador de NO, não havia ainda sido testada na $\mathrm{I} / \mathrm{R}$ hepática. Em nosso meio Krieger et $\mathrm{al}^{44}$ estudaram ratos com hipercolesterolemia e encontraram um efeito benéfico do SNAC, diminuindo a aterogênese. Recentemente, de Oliveira et al $^{45}$ avaliaram a expressão de genes hepáticos associados ao metabolismo de ácidos graxos em ratos com esteatose e encontraram, no grupo tratado com SNAC, uma menor expressão destes genes, mostrando indiretamente melhora da sobrecarga mitocondrial e do estresse oxidativo hepático na esteatose. A SNAC também se mostrou benéfica na lesão de I/R tecidual. Chen et al, ${ }^{46}$ em estudo experimental em ratos, avaliando lesão de I/R em músculo esquelético, demonstraram efeitos protetores da SNAC.

A administração de SNAC no grupo de ratos esteatóticos submetidos a isquemia e reperfusão não provocou alterações nas determinações de AST e ALT, provavelmente por razões discutidas anteriormente (desnutrição). Não foram observadas com a SNAC alterações significativas à distância (permeabilidade pulmonar medida pelo azul de Evans e sequestração de leucócitos avaliada pela determinação da mieloperoxidase pulmonar). O tratamento com SNAC também não alterou, de maneira significativa, todos os parâmetros avaliados no grupo não esteatótico. Promoveu apenas uma tendência a menor estresse oxidativo na porção isquêmica do fígado neste grupo (figura 18). No grupo esteatótico, no entanto, a SNAC promoveu uma melhora significativa na função mitocondrial pós lesão de I/R, 
tanto na avaliação do RCR (oxidativa) quanto do ADPO (fosforilativa) (figuras 22, 23, 24 e 25). Promoveu redução da hemorragia intraparenquimatosa, avaliada ao exame histológico, no fígado isquêmico (figuras 19, 20 e 21), e melhora significativa no estresse oxidativo na porção isquêmica do fígado do grupo esteatótico (figura 26).

O peroxinitrito, um radical livre altamente reativo, é formado pela combinação de NO com ânion superóxido. Em condições normais esta reação é prevenida pela remoção constante de NO pela hemoglobina. ${ }^{75}$ Durante as fases finais da reperfusão a produção de NO está aumentada devido a um aumento da expressão da iNOS (óxido nítrico sintase induzida), e esta produção excessiva de NO está relacionada àa lesão hepática pela formação de peroxinitrito. ${ }^{76,77} \mathrm{~A}$ S-nitroso-Nacetilcisteína, sendo um thiol doador de NO, quando em grandes quantidades pode produzir por si só peroxinitrito e estresse nitridativo. A administração de NO na fase inicial da isquemia pode regular a microcirculação hepática, e ao mesmo tempo diminuir a produção excessiva de NO nas fases finais da reperfusão, protegendo de maneira direta e indireta contra as lesões provocadas pela I/R. Desta forma a dose e o momento de administração de um doador de NO são pontos cruciais nos modelos de I/R hepáticas.

Em suma, pelo presente estudo, a esteatose promoveu na lesão de I/R um maior estresse oxidativo hepático e maior inflamação à distância. A SNAC não promoveu melhora na lesão de I/R no fígado de animais controle, sem esteatose grave. Todavia, a SNAC promoveu melhora significativa nesta mesma lesão no fígado de animais com esteatose acentuada. Mais estudos experimentais devem ser realizados para estabelecer a real ação desta droga, relativamente nova e promissora, sobre a isquemia e reperfusão em fígados esteatóticos, visando sua ulterior aplicação clínica. 
6-CONCLUSÕES 


\section{CONCLUSÕES}

Nas condições do presente trabalho pode-se concluir que:

1. A administração de S-nitroso-N-acetilcisteína em ratos controle, sem esteatose hepática grave, não reduziu as lesões resultantes da isquemia e reperfusão hepática.

2. A administração de S-nitroso-N-acetilcisteína em ratos com esteatose hepática acentuada reduziu significativamente as lesões hepáticas causadas pela isquemia e reperfusão do fígado. 
7 - ANEXOS 
TABELA 1 - Valores individuais dos níveis de aspartato aminotransferase (AST) $(\mathrm{U} / \mathrm{L})$, alanina aminotransferase (ALT) $(\mathrm{U} / \mathrm{L})$, extravasamento do corante azul de Evans no pulmão (Azul de Evans) ( $\mu \mathrm{g}$ de azul de Evans/g de tecido seco), mieloperoxidase no pulmão (DO a $490 \mathrm{~nm}$ ), razão de controle respiratório mitocondrial (RCR), razão de adenosina difosfato (ADP) sobre oxigênio (ADP/O) e malondialdeído (MDA) (nmol) nas porções isquêmica (Isquêmico) e não isquêmica (Não isq.) do fígado, do grupo I (ratos com dieta balanceada e solução salina).

\begin{tabular}{|c|c|c|c|c|c|c|c|c|c|c|}
\hline \multirow[t]{2}{*}{ ratos } & \multirow[t]{2}{*}{ AST } & \multirow[t]{2}{*}{ ALT } & \multirow{2}{*}{$\begin{array}{c}\text { Azul } \\
\text { de } \\
\text { Evans }\end{array}$} & \multirow[t]{2}{*}{ MPO } & \multicolumn{2}{|c|}{ RCR } & \multicolumn{2}{|c|}{ ADP/O } & \multicolumn{2}{|c|}{ MDA } \\
\hline & & & & & $\begin{array}{l}\text { Isquêmic } \\
\text { o }\end{array}$ & $\begin{array}{l}\text { Não } \\
\text { Isq. }\end{array}$ & $\begin{array}{l}\text { Isquêmic } \\
\text { o }\end{array}$ & $\begin{array}{l}\text { Não } \\
\text { Isq. }\end{array}$ & $\begin{array}{l}\text { Isquêmic } \\
\text { o }\end{array}$ & $\begin{array}{l}\text { Não } \\
\text { Isq. }\end{array}$ \\
\hline 1 & 2450 & 2220 & 560,4 & 0,203 & 2,50 & 3,54 & 1,76 & 1,76 & 1,20 & 1,00 \\
\hline 2 & 4080 & 2460 & 367,7 & 0,138 & 2,10 & 3,47 & 1,76 & 1,82 & 1,60 & 0,76 \\
\hline 3 & 2900 & 3670 & 274,1 & 0,093 & 2,50 & 2,59 & 1,64 & 1,91 & 4,40 & 0,98 \\
\hline 4 & 4260 & 3910 & 858,5 & 0,087 & 1,52 & 2,36 & 1,10 & 1,67 & 1,40 & 1,50 \\
\hline 5 & 4510 & 3000 & 961,8 & - & 2,64 & 2,92 & 1,62 & 1,62 & 2,90 & 1,60 \\
\hline 6 & 2470 & 2840 & 300,0 & 0,092 & 2,19 & 3,38 & 1,41 & 1,92 & 4,30 & 0,90 \\
\hline 7 & 6100 & 5620 & 496,5 & 0,113 & 1,65 & 2,64 & 1,12 & 1,70 & 4,50 & 0,16 \\
\hline 8 & 8110 & 9970 & 546,8 & 0,094 & 1,32 & 2,64 & 0,88 & 1,51 & 5,70 & 1,00 \\
\hline $\begin{array}{l}\text { Médi } \\
\text { a }\end{array}$ & 4360 & 4211 & 545,7 & 0,117 & 2,05 & 2,94 & 1,41 & 1,74 & 3,25 & 0,86 \\
\hline $\begin{array}{c}\text { Desvi } \\
0 \\
\text { padrã } \\
0 \\
\end{array}$ & 1948 & 2561 & 250,6 & 0,042 & 0,50 & 0,46 & 0,34 & 0,14 & 1,71 & 0,38 \\
\hline
\end{tabular}


TABELA 2 - Valores individuais dos níveis de aspartato aminotransferase (AST) $(\mathrm{U} / \mathrm{L})$, alanina aminotransferase $(\mathrm{ALT})(\mathrm{U} / \mathrm{L})$, extravasamento do corante azul de Evans no pulmão (Azul de Evans) ( $\mu \mathrm{g}$ de azul de Evans/g de tecido seco), mieloperoxidase no pulmão (DO a $490 \mathrm{~nm}$ ), razão de controle respiratório mitocondrial (RCR), razão de adenosina difosfato (ADP) sobre oxigênio (ADP/O) e malondialdeído (MDA) (nmol) nas porções isquêmica (Isquêmico) e não isquêmica (Não isq.) do fígado, do grupo II (ratos com dieta balanceada e S-Nitroso-Nacetilcisteína (SNAC)).

\begin{tabular}{|c|l|l|l|l|l|l|l|l|l|l|}
\hline ratos & AST & ALT & $\begin{array}{l}\text { Azul } \\
\text { de } \\
\text { Evans }\end{array}$ & MPO & \multicolumn{3}{|c|}{ RCR } & \multicolumn{2}{|c|}{ ADP/O } & \multicolumn{2}{|c|}{ MDA } \\
\hline Isquêmic & $\begin{array}{l}\text { Não } \\
\text { Isq. }\end{array}$ & $\begin{array}{l}\text { Isquêmic } \\
\text { o }\end{array}$ & $\begin{array}{l}\text { Não } \\
\text { Isq. }\end{array}$ & $\begin{array}{l}\text { Isquêmic } \\
\text { o }\end{array}$ & $\begin{array}{l}\text { Não } \\
\text { Isq. }\end{array}$ \\
\hline $\mathbf{1}$ & $\begin{array}{l}228 \\
0\end{array}$ & 1560 & 244,9 & 0,102 & 2,38 & 3,20 & 1,76 & 1,82 & 1,65 & 0,41 \\
\hline $\mathbf{2}$ & $\begin{array}{l}150 \\
0\end{array}$ & 1650 & 555,8 & 0,174 & 3,14 & 3,57 & 1,88 & 1,95 & 2,30 & 1,31 \\
\hline $\mathbf{3}$ & $\begin{array}{l}562 \\
0\end{array}$ & 6130 & 187,6 & 0,126 & 1,33 & 3,87 & 1,18 & 1,97 & 3,03 & 0,00 \\
\hline $\mathbf{4}$ & $\begin{array}{l}518 \\
0\end{array}$ & 3860 & 339,6 & 0,232 & 2,50 & 3,15 & 1,64 & 1,88 & 4,10 & 1,54 \\
\hline $\mathbf{5}$ & $\begin{array}{l}192 \\
0\end{array}$ & 1740 & 406,7 & 0,070 & 2,50 & 3,59 & 1,67 & 1,82 & 0,82 & 0,00 \\
\hline $\mathbf{6}$ & $\begin{array}{l}610 \\
0\end{array}$ & 4340 & 724,3 & 0,132 & 1,33 & 2,14 & 0,88 & 1,39 & 0,09 & 0,99 \\
\hline $\mathbf{7}$ & $\begin{array}{l}850 \\
0\end{array}$ & 8150 & 281,3 & 0,086 & 1,15 & 2,25 & 0,91 & 1,74 & 0,11 & 0,88 \\
\hline $\mathbf{8}$ & $\begin{array}{l}718 \\
0\end{array}$ & 5620 & 260,4 & 0,048 & 1,15 & 2,71 & 0,91 & 1,76 & 1,56 & 0,40 \\
\hline $\begin{array}{c}\text { Média } \\
478 \\
5\end{array}$ & 4131 & 375,1 & 0,121 & 1,94 & 3,06 & 1,35 & 1,81 & 1,71 & 0,69 \\
\hline $\begin{array}{l}\text { Desvio } \\
\text { padrã } \\
\mathbf{0}\end{array}$ & $\begin{array}{l}260 \\
2\end{array}$ & 2419 & 181,6 & 0,06 & 0,78 & 0,64 & 0,43 & 0,21 & 1,40 & 0,58 \\
\hline
\end{tabular}


TABELA 3 - Valores individuais dos níveis de aspartato aminotransferase (AST) $(\mathrm{U} / \mathrm{L})$, alanina aminotransferase (ALT) $(\mathrm{U} / \mathrm{L})$, extravasamento do corante azul de Evans no pulmão (Azul de Evans) ( $\mu \mathrm{g}$ de azul de Evans/g de tecido seco), mieloperoxidase no pulmão (DO a $490 \mathrm{~nm}$ ), razão de controle respiratório mitocondrial (RCR), razão de adenosina difosfato (ADP) sobre oxigênio (ADP/O) e malondialdeído (MDA) (nmol) nas porções isquêmica (Isquêmico) e não isquêmica (Não isq.) do fígado, do grupo III (ratos com dieta aproteica (esteatose acentuada) e solução salina).

\begin{tabular}{|c|c|c|c|c|c|c|c|c|c|c|}
\hline \multirow[t]{2}{*}{ ratos } & \multirow[t]{2}{*}{ AST } & \multirow[t]{2}{*}{ ALT } & \multirow{2}{*}{$\begin{array}{c}\text { Azul } \\
\text { de } \\
\text { Evans }\end{array}$} & \multirow[t]{2}{*}{ MPO } & \multicolumn{2}{|c|}{ RCR } & \multicolumn{2}{|c|}{ ADP/O } & \multicolumn{2}{|c|}{ MDA } \\
\hline & & & & & $\begin{array}{l}\text { Isquêmic } \\
\text { o }\end{array}$ & $\begin{array}{l}\text { Não } \\
\text { Isq. }\end{array}$ & $\begin{array}{l}\text { Isquêmi } \\
\text { co }\end{array}$ & $\begin{array}{l}\text { Não } \\
\text { Isq. }\end{array}$ & $\begin{array}{l}\text { Isquêmic } \\
\text { o }\end{array}$ & $\begin{array}{l}\text { Não } \\
\text { Isq. }\end{array}$ \\
\hline 1 & $\begin{array}{l}215 \\
0\end{array}$ & 250 & 1503,9 & 0,108 & 1,91 & 3,50 & 1,25 & 1,78 & 16,30 & 16,90 \\
\hline 2 & $\begin{array}{l}149 \\
0\end{array}$ & 450 & 2902,4 & 0,465 & 1,13 & 3,20 & 1,11 & 1,82 & 4,15 & 5,00 \\
\hline 3 & 550 & 150 & 2662,2 & 0,190 & 2,00 & 2,22 & 1,62 & 1,76 & 2,06 & 1,70 \\
\hline 4 & 710 & 350 & 1017,1 & 0,300 & 2,21 & 2,63 & 1,55 & 1,60 & 5,50 & 3,90 \\
\hline 5 & 940 & 470 & 362,9 & 0,092 & 2,70 & 2,38 & 1,55 & 1,65 & 10,80 & 2,70 \\
\hline 6 & 880 & 130 & 240,4 & 0,108 & 2,40 & 2,83 & 1,48 & 1,51 & 25,00 & 21,90 \\
\hline 7 & 950 & 152 & 1376,5 & 0,106 & 1,75 & 1,44 & 1,35 & 1,40 & 20,70 & 20,80 \\
\hline 8 & 337 & 290 & 1922,9 & 0,117 & 2,53 & 2,54 & 1,48 & 1,74 & 10,50 & 10,20 \\
\hline 9 & 960 & 280 & 219,8 & 0,137 & 2,59 & 2,45 & 1,59 & 1,51 & 13,30 & 3,60 \\
\hline Média & 996 & 280 & 1356,5 & 0,180 & 2,14 & 2,58 & 1,44 & 1,64 & 12,03 & 9,63 \\
\hline $\begin{array}{c}\text { Desvio } \\
\text { padrã } \\
0\end{array}$ & 537 & 126 & 1004,9 & 0,125 & 0,50 & 0,59 & 0,17 & 0,15 & 7,67 & 8,14 \\
\hline
\end{tabular}


TABELA 4 - Valores individuais dos níveis de aspartato aminotransferase (AST) $(\mathrm{U} / \mathrm{L})$, alanina aminotransferase (ALT) (U/L), extravasamento do corante azul de Evans no pulmão (Azul de Evans) ( $\mu \mathrm{g}$ de azul de Evans/g de tecido seco), mieloperoxidase no pulmão (DO a $490 \mathrm{~nm}$ ), razão de controle respiratório mitocondrial $(R C R)$, razão de adenosina difosfato (ADP) sobre oxigênio (ADP/O) e malondialdeído (MDA) (nmol) nas porções isquêmica (Isquêmico) e não isquêmica (Não isq.) do fígado, do grupo IV (ratos com dieta aproteica (esteatose acentuada) e S-Nitroso-N-acetilcisteína (SNAC)).

\begin{tabular}{|c|c|c|c|c|c|c|c|c|c|c|}
\hline \multirow[t]{2}{*}{ ratos } & \multirow[t]{2}{*}{ AST } & \multirow[t]{2}{*}{ ALT } & \multirow{2}{*}{$\begin{array}{c}\text { Azul } \\
\text { de } \\
\text { Evans }\end{array}$} & \multirow[t]{2}{*}{ MPO } & \multicolumn{2}{|c|}{ RCR } & \multicolumn{2}{|c|}{ ADP/O } & \multicolumn{2}{|c|}{ MDA } \\
\hline & & & & & $\begin{array}{l}\text { Isquêmic } \\
\text { o }\end{array}$ & $\begin{array}{l}\text { Não } \\
\text { Isq. }\end{array}$ & $\begin{array}{l}\text { Isquêmi } \\
\text { co }\end{array}$ & $\begin{array}{l}\text { Não } \\
\text { Isq. }\end{array}$ & $\begin{array}{l}\text { Isquêmic } \\
\text { o }\end{array}$ & $\begin{array}{l}\text { Não } \\
\text { Isq. }\end{array}$ \\
\hline 1 & 872 & 90 & 396,7 & 0,093 & 2,50 & 3,75 & 1,61 & 1,78 & 4,20 & 5,60 \\
\hline 2 & 934 & 140 & 412,7 & 0,092 & 2,91 & 2,57 & 1,70 & 1,70 & 4,75 & 5,00 \\
\hline 3 & 820 & 260 & 2518,4 & 0,206 & 3,40 & 2,71 & 1,95 & 1,88 & 4,87 & 4,80 \\
\hline 4 & 138 & 870 & 3946,6 & 0,132 & 2,53 & 3,44 & 1,62 & 1,99 & 0,40 & 2,30 \\
\hline 5 & 820 & 330 & 945,5 & 0,174 & 3,20 & 3,33 & 1,82 & 1,82 & 7,90 & 2,20 \\
\hline 6 & $\begin{array}{l}102 \\
0\end{array}$ & 370 & 886,9 & 0,052 & 3,08 & 2,83 & 1,69 & 1,79 & 5,50 & 3,00 \\
\hline 7 & $\begin{array}{l}125 \\
0\end{array}$ & 450 & 1006,9 & 0,154 & 3,11 & 2,17 & 1,69 & 1,69 & - & - \\
\hline 8 & 570 & 181 & 681,1 & 0,186 & 2,54 & 3,44 & 1,71 & 1,97 & 12,30 & 12,00 \\
\hline 9 & $\begin{array}{l}159 \\
0\end{array}$ & 228 & 950,0 & 0,177 & 1,85 & 3,00 & 1,18 & 1,91 & 10,17 & 7,30 \\
\hline Média & 890 & 324 & 1305,0 & 0,141 & 2,79 & 3,03 & 1,66 & 1,84 & 6,26 & 5,28 \\
\hline Desvio & 406 & 234 & 1171,5 & 0,052 & 0,48 & 0,50 & 0,21 & 0,11 & 3,74 & 3,23 \\
\hline
\end{tabular}




\begin{tabular}{|c|l|l|l|l|l|l|l|l|l|}
\hline $\begin{array}{c}\text { padrã } \\
\mathbf{0}\end{array}$ & & & & & & & & & \\
\hline
\end{tabular}

Tabela 5 - Valores individuais das variáveis histopatológicas dos lobos hepáticos isquêmicos (Isq) e não isquêmicos (Não Isq) do grupo I (ratos com dieta balanceada e solução salina): A) tumefação hepatocelular (Tum), retração hepatocelular (Ret), necrose hepatocelular coagulativa (Necr), presença de polimorfonucleares sinusoidais (PMN), hemorragia intraparenquimatosa (Hem) quantificadas seguindo um escore de 0 a 3: $0=$ ausente; $1=$ focal ou leve; $2=$ moderada e $3=$ intensa. B) Esteatose microvesicular (Est micro) e macrovesicular (Est macro) utilizando o escore: $0=$ não detectada na amostra; 1 = presente em até $25 \%$ dos hepatócitos; $2=$ presente em até $50 \%$ dos hepatócitos; $3=$ presente em até $70 \%$ dos hepatócitos e 4= presente em mais de $80 \%$ dos hepatócitos. C) Esteatose total (Est total) descrita em porcentagem de hepatócitos com esteatose. 
Tabela 6 - Valores individuais das variáveis histopatológicas dos lobos hepáticos isquêmicos (Isq) e não isquêmicos (Não Isq) do grupo II (ratos com dieta balanceada e S-Nitroso-N-acetilcisteína (SNAC)): A) tumefação hepatocelular (Tum), retração hepatocelular (Ret), necrose hepatocelular coagulativa (Necr), presença de polimorfonucleares sinusoidais $(\mathrm{PMN})$, hemorragia intraparenquimatosa (Hem) quantificadas seguindo um escore de 0 a 3 : $0=$ ausente; $1=$ focal ou leve; 2=moderada e 3=intensa. B) Esteatose microvesicular (Est micro) e macrovesicular (Est macro) utilizando o escore: $0=$ não detectada na amostra; 1 = presente em até $25 \%$ dos hepatócitos; $2=$ presente em até $50 \%$ dos hepatócitos; $3=$ presente em até $70 \%$ dos hepatócitos e 4= presente em mais de $80 \%$ dos hepatócitos. C) Esteatose total (Est total) descrita em porcentagem de hepatócitos com esteatose.

\begin{tabular}{|c|c|l|l|l|l|l|l|l|l|}
\hline Ratos & $\begin{array}{c}\text { Lobo } \\
\text { hepático }\end{array}$ & Tum & Ret & Necr & PMN & Hem & $\begin{array}{c}\text { Est } \\
\text { micro }\end{array}$ & $\begin{array}{c}\text { Est } \\
\text { macro }\end{array}$ & $\begin{array}{c}\text { Est } \\
\text { total }\end{array}$ \\
\hline \multirow{2}{*}{$\mathbf{1}$} & Isq & 2 & 1 & 4 & 1 & 1 & 1 & 0 & 20 \\
\cline { 2 - 9 } & Não Isq & 1 & 1 & 0 & 0 & 0 & 1 & 0 & 20 \\
\hline \multirow{2}{*}{2} & Isq & 1 & 1 & 4 & 2 & 1 & 0 & 0 & 0 \\
\cline { 2 - 10 } & Não Isq & 1 & 1 & 0 & 1 & 0 & 1 & 0 & 20 \\
\hline \multirow{2}{*}{3} & Isq & 1 & 1 & 2 & 1 & 0 & 2 & 0 & 40 \\
\cline { 2 - 10 } & Não Isq & 0 & 0 & 0 & 0 & 0 & 1 & 0 & 20 \\
\hline \multirow{2}{*}{4} & Isq & 1 & 1 & 1 & 1 & 0 & 3 & 0 & 70 \\
\cline { 2 - 9 } & Não Isq & 1 & 1 & 0 & 0 & 0 & 2 & 0 & 50 \\
\hline \multirow{2}{*}{5} & Isq & 1 & 1 & 4 & 2 & 1 & 2 & 0 & 40 \\
\cline { 2 - 9 } & Não Isq & 2 & 1 & 0 & 0 & 0 & 1 & 0 & 20 \\
\hline \multirow{2}{*}{$\mathbf{6}$} & Isq & 1 & 1 & 1 & 1 & 0 & 1 & 0 & 5 \\
\cline { 2 - 9 } & Não Isq & 0 & 1 & 0 & 0 & 0 & 0 & 0 & 0 \\
\hline \multirow{2}{*}{7} & Isq & 3 & 1 & 0 & 1 & 0 & 1 & 1 & 25 \\
\cline { 2 - 9 } & Não Isq & 0 & 0 & 0 & 0 & 0 & 1 & 1 & 30 \\
\hline \multirow{2}{*}{8} & Isq & 3 & 1 & 2 & 2 & 1 & 2 & 2 & 70 \\
\cline { 2 - 9 } & Não Isq & 0 & 0 & 0 & 0 & 0 & 2 & 2 & 80 \\
\hline
\end{tabular}




\begin{tabular}{|c|c|c|c|c|c|c|c|c|c|}
\hline Ratos & $\begin{array}{c}\text { Lobo } \\
\text { hepático }\end{array}$ & Tum & Ret & Necr & PMN & Hem & $\begin{array}{c}\text { Est } \\
\text { micro }\end{array}$ & $\begin{array}{c}\text { Est } \\
\text { macro }\end{array}$ & $\begin{array}{c}\text { Est } \\
\text { total }\end{array}$ \\
\hline \multirow{2}{*}{1} & Isq & 1 & 1 & 2 & 2 & 1 & 1 & 0 & 10 \\
\hline & Não Isq & - & - & - & - & - & - & - & - \\
\hline \multirow{2}{*}{2} & Isq & 2 & 1 & 1 & 1 & 0 & 1 & 0 & 20 \\
\hline & Não Isq & 0 & 1 & 0 & 0 & 0 & 1 & 0 & 20 \\
\hline \multirow{2}{*}{3} & Isq & 1 & 2 & 3 & 1 & 0 & 3 & 1 & 70 \\
\hline & Não Isq & 1 & 1 & 0 & 0 & 0 & 3 & 1 & 75 \\
\hline \multirow{2}{*}{4} & Isq & 2 & 1 & 1 & 1 & 0 & 1 & 0 & 10 \\
\hline & Não Isq & 0 & 0 & 0 & 0 & 0 & 1 & 0 & 10 \\
\hline \multirow{2}{*}{5} & Isq & 2 & 1 & 2 & 2 & 0 & 2 & 1 & 50 \\
\hline & Não Isq & 0 & 0 & 0 & 0 & 0 & 2 & 1 & 60 \\
\hline \multirow{2}{*}{6} & Isq & 3 & 1 & 1 & 1 & 1 & 1 & 1 & 30 \\
\hline & Não Isq & 0 & 0 & 0 & 0 & 0 & 1 & 1 & 15 \\
\hline \multirow{2}{*}{7} & Isq & 1 & 1 & 2 & 1 & 1 & 0 & 0 & 0 \\
\hline & Não Isq & 0 & 0 & 0 & 0 & 0 & 0 & 0 & 0 \\
\hline \multirow{2}{*}{8} & Isq & 3 & 0 & 2 & 1 & 1 & 1 & 0 & 10 \\
\hline & Não Isq & 0 & 0 & 0 & 0 & 0 & 1 & 0 & 10 \\
\hline
\end{tabular}

Tabela 7 - Valores individuais das variáveis histopatológicas dos lobos hepáticos isquêmicos (Isq) e não isquêmicos (Não Isq) do grupo III (ratos com dieta aproteica (esteatóticos) e solução salina): A) tumefação hepatocelular (Tum), retração hepatocelular (Ret), necrose hepatocelular coagulativa (Necr), presença de polimorfonucleares sinusoidais (PMN), hemorragia intraparenquimatosa (Hem) quantificadas seguindo um escore de 0 a 3: $0=$ ausente; 1=focal ou leve; 2=moderada e 3=intensa. B) Esteatose microvesicular (Est micro) e macrovesicular (Est macro) utilizando o escore: $0=$ não detectada na amostra; 1 = presente em até $25 \%$ dos hepatócitos; $2=$ presente em até $50 \%$ dos hepatócitos; $3=$ presente em até $70 \%$ dos hepatócitos e $4=$ presente em mais de $80 \%$ dos hepatócitos. C) Esteatose total (Est total) descrita em porcentagem de hepatócitos com esteatose.

\begin{tabular}{|c|c|c|c|c|c|c|c|c|c|}
\hline Ratos & $\begin{array}{c}\text { Lobo } \\
\text { hepático }\end{array}$ & Tum & Ret & Necr & PMN & Hem & $\begin{array}{c}\text { Est } \\
\text { micro }\end{array}$ & $\begin{array}{c}\text { Est } \\
\text { macro }\end{array}$ & $\begin{array}{c}\text { Est } \\
\text { total }\end{array}$ \\
\hline
\end{tabular}




\begin{tabular}{|c|c|c|c|c|c|c|c|c|c|}
\hline \multirow{2}{*}{1} & Isq & 1 & 1 & 3 & 2 & 2 & 3 & 1 & 70 \\
\hline & Não Isq & 1 & 1 & 0 & 0 & 0 & 4 & 1 & 80 \\
\hline \multirow{2}{*}{2} & Isq & 3 & 1 & 1 & 2 & 3 & 4 & 4 & 95 \\
\hline & Não Isq & 1 & 0 & 0 & 1 & 1 & 4 & 1 & 80 \\
\hline \multirow{2}{*}{3} & Isq & 2 & 2 & 2 & 1 & 2 & 1 & 1 & 20 \\
\hline & Não Isq & 2 & 1 & 0 & 0 & 0 & 1 & 1 & 25 \\
\hline \multirow{2}{*}{4} & Isq & 3 & 1 & 1 & 1 & 2 & 2 & 0 & 40 \\
\hline & Não Isq & 3 & 0 & 0 & 0 & 0 & 2 & 0 & 30 \\
\hline \multirow{2}{*}{5} & Isq & 2 & 2 & 3 & 2 & 3 & 2 & 2 & 70 \\
\hline & Não Isq & 2 & 0 & 0 & 1 & 0 & 2 & 2 & 80 \\
\hline \multirow{2}{*}{6} & Isq & 2 & 1 & 1 & 1 & 3 & 2 & 1 & 50 \\
\hline & Não Isq & 1 & 1 & 0 & 0 & 0 & 2 & 1 & 60 \\
\hline \multirow{2}{*}{7} & Isq & 2 & 0 & 1 & 2 & 3 & 1 & 0 & 20 \\
\hline & Não Isq & 3 & 0 & 0 & 0 & 0 & 1 & 0 & 10 \\
\hline \multirow{2}{*}{8} & Isq & 3 & 1 & 1 & 2 & 2 & 2 & 0 & 50 \\
\hline & Não Isq & 1 & 0 & 0 & 0 & 0 & 2 & 0 & 40 \\
\hline \multirow{2}{*}{9} & Isq & 3 & 1 & 1 & 2 & 1 & 2 & 0 & 40 \\
\hline & Não Isq & 1 & 0 & 0 & 0 & 0 & 2 & 0 & 50 \\
\hline
\end{tabular}

Tabela 8 - Valores individuais das variáveis histopatológicas dos lobos hepáticos isquêmicos (Isq) e não isquêmicos (Não Isq) do grupo IV (ratos com dieta aproteica (esteatóticos) e S-Nitroso-N-acetilcisteína (SNAC)): A) tumefação hepatocelular (Tum), retração hepatocelular (Ret), necrose hepatocelular coagulativa (Necr), presença de polimorfonucleares sinusoidais (PMN), hemorragia intraparenquimatosa (Hem) quantificadas seguindo um escore de 0 a 3: 0= ausente; 1=focal ou leve; 2=moderada e 3=intensa. B) Esteatose microvesicular (Est micro) e macrovesicular (Est macro) utilizando o escore: $0=$ não detectada na amostra; $1=$ presente em até $25 \%$ dos hepatócitos; $2=$ presente em até $50 \%$ dos hepatócitos; $3=$ presente em até $70 \%$ dos hepatócitos e 4= presente em mais de $80 \%$ dos hepatócitos. C) Esteatose total (Est total) descrita em porcentagem de hepatócitos com esteatose.

\begin{tabular}{|c|c|c|c|c|c|c|c|c|c|}
\hline Ratos & $\begin{array}{c}\text { Lobo } \\
\text { hepático }\end{array}$ & Tum & Ret & Necr & PMN & Hem & $\begin{array}{c}\text { Est } \\
\text { mic ro }\end{array}$ & $\begin{array}{c}\text { Est } \\
\text { macro }\end{array}$ & $\begin{array}{c}\text { Est } \\
\text { total }\end{array}$ \\
\hline
\end{tabular}




\begin{tabular}{|c|c|c|c|c|c|c|c|c|c|}
\hline \multirow{2}{*}{1} & Isq & 2 & 1 & 3 & 2 & 3 & 3 & 1 & 80 \\
\hline & Não Isq & 1 & 1 & 1 & 1 & 0 & 3 & 1 & 75 \\
\hline \multirow{2}{*}{2} & Isq & 1 & 1 & 3 & 2 & 1 & 3 & 1 & 70 \\
\hline & Não Isq & 1 & 1 & 0 & 0 & 0 & 3 & 1 & 65 \\
\hline \multirow{2}{*}{3} & Isq & 2 & 2 & 3 & 2 & 1 & 2 & 2 & 60 \\
\hline & Não Isq & 1 & 1 & 0 & 0 & 0 & 2 & 2 & 70 \\
\hline \multirow{2}{*}{4} & Isq & 2 & 1 & 1 & 2 & 2 & 1 & 1 & 15 \\
\hline & Não Isq & 0 & 0 & 0 & 0 & 0 & 1 & 1 & 15 \\
\hline \multirow{2}{*}{5} & Isq & 3 & 1 & 1 & 2 & 1 & 1 & 0 & 10 \\
\hline & Não Isq & 3 & 0 & 0 & 0 & 0 & 1 & 0 & 5 \\
\hline \multirow{2}{*}{6} & Isq & 2 & 1 & 1 & 1 & 1 & 2 & 2 & 90 \\
\hline & Não Isq & 1 & 0 & 0 & 0 & 0 & 2 & 2 & 80 \\
\hline \multirow{2}{*}{7} & Isq & 3 & 1 & 1 & 1 & 1 & 4 & 0 & 80 \\
\hline & Não Isq & 1 & 0 & 0 & 1 & 0 & 4 & 1 & 90 \\
\hline \multirow{2}{*}{8} & Isq & 2 & 0 & 0 & 1 & 0 & 3 & 1 & 80 \\
\hline & Não Isq & 1 & 0 & 0 & 0 & 0 & 3 & 1 & 80 \\
\hline \multirow{2}{*}{9} & Isq & 2 & 1 & 1 & 1 & 3 & 0 & 0 & 0 \\
\hline & Não Isq & 1 & 0 & 0 & 0 & 0 & 0 & 0 & 0 \\
\hline
\end{tabular}

\section{8 - REFERÊNCIAS BIBLIOGRÁFICAS}


Referências Bibliográficas

1- Hilden M, Christoffersen P, Juhl E, Dalgaard JB. Liver histology in a 'normal' population--examinations of 503 consecutive fatal traffic casualties. Scand $J$ Gastroenterol. 1977;12(5):593-7. 
2- Browning J, Szczepaniak L, Dobbins R, Nuremberg P, Horton J, Cohen J. Prevalence of hepatic steatosis in an urban population in the United States: impact of ethnicity. Hepatology. 2004;40:1387-95.

3- Ryan CK, Johnson LA, Germin BI, Marcos A. One hundred consecutive hepatic biopsies in the workup of living donors for right lobe liver transplantation. Liver Transpl. 2002;8:1114-22.

4- Nomura H, Kashiwagi S, Hayashi J, Kajiyama W, Tani S, Goto M. Prevalence of fatty liver in a general population of Okinawa, Japan. Jpn J Med. 1988;27: 142-9.

5- Tominaga K, Kurata JH, Chen YK, Fujimoto E, Miyagawa S, Abe I. Prevalence of fatty liver in Japanese children and relationship to obesity. An epidemiological ultrasonographic survey. Dig Dis Sci. 1995;40:2002-9.

6- Bellentani S, Saccoccio G, Masutti F, Croce LS, Brandi G, Sasso F. Prevalence of and risk factors for hepatic steatosis in northern Italy. Ann Intern Med. 2000;132:112-7.

7- Gupte P, Amarapurkar D, Agal S, Baijal R, Kulshrestha P, Pramanik S. Nonalcoholic steatohepatitis in type 2 diabetes mellitus. J Gastroenterol Hepatol. 2004;19:854-8.

8- Del Gaudio A, Boschi L, Del Gaudio GA, Mastrangelo L, Munari D. Liver damage in obese patients. Obes Surg. 2002;12:802-4.

9- Fromenty B Pharmacol Ther 1995 Fromenty B, Pessayre D. Inhibition of mitochondrial beta-oxidation as a mechanism of hepatotoxicity. Pharmacol Ther. 1995;67(1):101-54.

10- Natarajan SK, Basivireddy J, Ramachandran A, Thomas S, Ramamoorthy P, Pulimood AB, Jacob M, Balasubramanian KA. Renal damage in experimentally- 
induced cirrhosis in rats: Role of oxygen free radicals. Hepatology. 2006 Jun;43(6):1248-56.

11- Tilg H, Diehl AM. Cytokines in alcoholic and nonalcoholic steatohepatitis. $N$ Engl J Med 2000;343:1467-76.

12- Leclercq IA, Farrell GC, Schriemer R, Robertson GR. Leptin is essential for the hepatic fibrogenic response to chronic liver injury. J Hepatol. 2002;37:206-13.

13- Hui JM, Hodge A, Farrell GC, Kench JG, Kriketos A, George J. Beyond insulin resistance in NASH: TNF-alpha or adiponectin? Hepatology. 2004;40:46-54.

14- Feldstein AE, Werneburg NW, Canbay A, Guicciardi ME, Bronk SF, Rydzewski R. Free fatty acids promote hepatic lipotoxicity by stimulating TNF-alpha expression via a lysosomal pathway. Hepatology. 2004;40:185-94.

15- Sanyal AJ, Campbell-Sargent C, Mirshahi F, Rizzo WB, Contos MJ, Sterling RK. Nonalcoholic steatohepatitis: association of insulin resistance and mitochondrial abnormalities. Gastroenterology. 2001;120:1183-92.

16- Machado MC, da Cunha JE, Margarido NF, Bevilacqua RG, Bacchella T, Goncalez Y, Goncalves EL. [Liver transplantation. Experimental study. I. Orthotopic technic] AMB Rev Assoc Med Bras. 1972 Jul;18(7):259-64.

17- Margarido NF. [Functional and histological aspects of the liver after ischemia. Experimental study in dogs] Rev Hosp Clin Fac Med Sao Paulo. 1973 JulAug;28(4):203-11.

18- da Cunha JE, Cesar Machado MC, Behmer OA, Margarido NF, Bacchella T, Goncalez Y, Goncalves EL. [Vascular lesions associated with experimental homologous liver transplantation] AMB Rev Assoc Med Bras. 1976 Jan;22(1):813. 
19- Granger DN, Stokes KY, Shigematsu T, Cerwinka WH, Tailor A, Krieglstein CF. Splanchnic ischaemia-reperfusion injury: mechanistic insights provided by mutant mice. Acta Physiol Scand. 2001 Sep;173(1):83-91.

20- Hayashi M, Tokunaga Y, Fujita T, Tanaka K, Yamaoka Y, Ozawa K. The effects of cold preservation on steatotic graft viability in rat liver transplantation. Transplantation. 1993 Aug;56(2):282-7.

21- Teramoto K, Bowers JL, Kruskal JB, Clouse ME. Hepatic microcirculatory changes after reperfusion in fatty and normal liver transplantation in the rat. Transplantation. 1993 Nov;56(5):1076-82.

22- Hui AM, Kawasaki S, Makuuchi M, Nakayama J, Ikegami T, Miyagawa S. Liver injury following normothermic ischemia in steatotic rat liver. Hepatology. 1994 Nov;20(5):1287-93.

23- Koneru B, Reddy MC, dela Torre AN, Patel D, Ippolito T, Ferrante RJ. Studies of hepatic warm ischemia in the obese Zucker rat. Transplantation. $1995 \mathrm{Apr}$ 15;59(7):942-6.

24- Glantzounis GK, Salacinski HJ, Yang W, Davidson BR, Seifalian AM. The contemporary role of antioxidant therapy in attenuating liver ischemia-reperfusion injury: a review. Liver Transpl. 2005 Sep;11(9):1031-47.

25- Behrns KE, Tsiotos GG, DeSouza NF, Krishna MK, Ludwig J, Nagorney DM. Hepatic steatosis as a potential risk factor for major hepatic resection. $J$ Gastrointest Surg. 1998 May-Jun;2(3):292-8.

26- Belghiti J, Hiramatsu K, Benoist S, Massault P, Sauvanet A, Farges O. Seven hundred forty-seven hepatectomies in the 1990s: an update to evaluate the actual risk of liver resection. J Am Coll Surg. 2000 Jul;191(1):38-46. 
27- Vetelainen R, van Vliet A, Gouma DJ, van Gulik TM. Steatosis as a risk factor in liver surgery. Ann Surg. 2007 Jan;245(1):20-30.

28- Sun CK, Zhang XY, Zimmermann A, Davis G, Wheatley AM. Effect of ischemiareperfusion injury on the microcirculation of the steatotic liver of the Zucker rat. Transplantation. 2001 Nov 27;72(10):1625-31.

29- Fukumori T, Ohkohchi N, Tsukamoto S, Satomi S. The mechanism of injury in a steatotic liver graft during cold preservation. Transplantation. 1999 Jan 27;67(2):195-200.

30- Todo S, Demetris AJ, Makowka L, Teperman L, Podesta L, Shaver T, Tzakis A,Starzl TE. Primary nonfunction of hepatic allografts with preexisting fatty infiltration. Transplantation. 1989 May;47(5):903-5.

31- Seifalian AM, Chidambaram V, Rolles K, Davidson BR. In vivo demonstration of impaired microcirculation in steatotic human liver grafts. Liver Transpl Surg. 1998 Jan;4(1):71-7.

32- Takahashi K, Hakamada K, Totsuka E, Umehara Y, Sasaki M. Warm ischemia and reperfusion injury in diet-induced canine fatty livers. Transplantation. 2000 May 27;69(10):2028-34.

33- Nardo B, Grattagliano I, Domenicali M, Caraceni P, Catena F, Santoni B, Turi P, Cavallari G, Dall'Agata M, Trevisani F, Bernardi M, Cavallari A. Mitochondrial oxidative injury in rat fatty livers exposed to warm ischemia-reperfusion. Transplant Proc. 2000;32(1):51.

34- Berson A, De Beco V, Letteron P, Robin MA, Moreau C, El Kahwaji J, Verthier N, Feldmann G, Fromenty B, Pessayre D. Steatohepatitis-inducing drugs cause mitochondrial dysfunction and lipid peroxidation in rat hepatocytes. Gastroenterology. 1998 Apr;114(4):764-74. 
35- Lehmann TG, Wheeler MD, Schwabe RF, Connor HD, Schoonhoven R, Bunzendahl H, Brenner DA, Jude Samulski R, Zhong Z, Thurman RG. Gene delivery of $\mathrm{Cu} / \mathrm{Zn}$-superoxide dismutase improves graft function after transplantation of fatty livers in the rat. Hepatology. 2000 Dec;32(6):1255-64.

36- Nakano $\mathrm{H}$, Nagasaki $\mathrm{H}$, Barama A. The effects of $n$-acetylcysteine and antiintercellular adhesion molecule-1 monoclonal antibody against ischemiareperfusion injury of the rat steatotic liver produced by a choline-methioninedeficient diet. Hepatology. 1997; 26: 670.

37- Soltys K, Dikdan G, Koneru B. Oxidative stress in fatty livers of obese Zucker rats: rapid amelioration and improved tolerance to warm ischemia with tocopherol. Hepatology. 2001 Jul;34(1):13-8.

38- Oliveira CP, Gayotto LC, Tatai C, Della Nina BI, Lima ES, Abdalla DS, Lopasso FP, Laurindo FR, Carrilho FJ. Vitamin C and vitamin E in prevention of Nonalcoholic Fatty Liver Disease (NAFLD) in choline deficient diet fed rats. Nutr J. 2003 Oct 7;2:9.

39- Nakano H, Boudjema K, Alexandre E, Imbs P, Chenard MP, Wolf P, Cinqualbre J, Jaeck D. Protective effects of $\mathrm{N}$-acetylcysteine on hypothermic ischemiareperfusion injury of rat liver. Hepatology. 1995 Aug;22(2):539-45.

40- Di Giorno C, Pinheiro HS, Heinke T, Franco MF, Galante NZ, Pacheco-Silva A, Camara NO. Beneficial effect of $\mathrm{N}$-acetyl-cysteine on renal injury triggered by ischemia and reperfusion. Transplant Proc. 2006 Nov;38(9):2774-6.

41- Caglikulekci M, Dirlik M, Pata C, Plasse M, Tamer L, Ogetman Z, Ercan B. Effect of $\mathrm{N}$-acetylcysteine on blood and tissue lipid peroxidation in lipopolysaccharideinduced obstructive jaundice. J Invest Surg. 2006 May-Jun;19(3):175-84. 
42- Diniz YS, Rocha KK, Souza GA, Galhardi CM, Ebaid GM, Rodrigues HG, Novelli Filho JL, Cicogna AC, Novelli EL. Effects of N-acetylcysteine on sucrose-rich diet-induced hyperglycaemia, dyslipidemia and oxidative stress in rats. Eur $\mathrm{J}$ Pharmacol. 2006 Aug 14;543(1-3):151-7.

43- Valko M, Leibfritz D, Moncol J, Cronin MT, Mazur M, Telser J. Free radicals and antioxidants in normal physiological functions and human disease. Int J Biochem Cell Biol. 2007;39(1):44-84.

44- Krieger MH, Santos KF, Shishido SM, Wanschel AC, Estrela HF, Santos L, De Oliveira MG, Franchini KG, Spadari-Bratfisch RC, Laurindo FR. Antiatherogenic effects of S-nitroso-N-acetylcysteine in hypercholesterolemic LDL receptor knockout mice. Nitric Oxide. 2006 Feb;14(1):12-20.

45- de Oliveira CP, Stefano JT, de Lima VM, de Sa SV, Simplicio FI, de Mello ES, Correa-Giannella ML, Alves VA, Laurindo FR, de Oliveira MG, Giannella-Neto D, Carrilho FJ. Hepatic gene expression profile associated with non-alcoholic steatohepatitis protection by S-nitroso-N-acetylcysteine in ob/ob mice. J Hepatol. 2006 Nov;45(5):725-33.

46- Chen LE, Seaber AV, Nasser RM, Stamler JS, Urbaniak JR. Effects of S-nitroso$\mathrm{N}$-acetylcysteine on contractile function of reperfused skeletal muscle. Am J Physiol. 1998 Mar;274(3 Pt 2):R822-9.

47- Gonçalez Y, Silva SM, Machado MCC, Bettarelo A. Efeito de regimes dietéticos diversos e ingestão "ad libitum" no conteúdo enzimático do pâncreas do rato. Rev Hosp Clin Fac Med S paulo 40(4): 177-182, 1985.

48- Gonçalez Y, Silva SM, Machado MCC, Bettarelo A. Protective effect of a proteinfree diet in acute experimental pancreatitis. Braz J Med Biol Res, 22: 477-483, 1989. 
49- Patel S, Pachter L, Yee $\mathrm{H}$ et al. Topical hepatic hypothermia attenuates pulmonary injury after hepatic ischemia and reperfusion. J Am Coll of Surg. 2000; 191: 650-656.

50- Canedo LF, Tese de Doutorado, Faculdade Medicina da Universidade de São Paulo, 2005.

51- Jancar S, GiaccobiG, Mariano M, Mencia-Huerta JM, Sirois P, Braquet P. Immune complex induced pancreatitis effect of BN 52021, a selective antaginist of platelet activanting factor. Prostaglandins. 1988; 35: 757.

52- Coelho AMM, Machado MCC, Sampietre SN et al. Hepatic damage during acute pancreatitis in the rat. Bras J Med Biol Res. 1997; 30: 947-952.

53- Estabrook R.W. Mitochondrial respiratory control and the polarographic measurement of ADP/O ratios. In: Estabrook RW \& Pullman ME, eds. Methods in Enzymology. New York: Academic Press, 1967: 41-47.

54- Chance B, Willians GR. A simple and rapid assay of oxidative phosphorylation. Nature. 1955; 175: 1120-1121.

55- Lowry OH, Rosebrough NJ, Farr AL, Randall RJ. Protein measurement with the folin phenol reagent. J Biol Cem. 1951;193:265-276.

56- Goldblum SE, Wu KM, Jay M. Lung myeloperoxidase as a measure of pulmonary leukostasis in rabbits. J Appl Physiol. 1985;59:1978-1985.

57- Warren JS, Yabroff KR, Mandel DM, Johnson KJ, Ward PA. Role of O2- in the neutrophil recruitment into site of dermal and pulmonary vasculitis. Free Radic Biolo Med. 1990;8:163-172.

58- Henson P, Zanolary B, Scwartzman NA, Hong S. Intracellular control of human neutrophil secretion. J Immunol. 1978;121:851-855. 
59- Soriano GS, Liaudet L, Szabó E et al. Resistance to acute septic peritonitis in poly(ADP-ribose) polymerase-1-deficient mice. Shock. 2002;17: 286-292.

60- Altman DG. Practical statistics for medical research. 1a ed. Londres: Chapman \& Halll; 1991.

61- Numro BH. Statistical methods for health care research. $4^{\mathrm{a}}$ ed. Portland: Lippincott; 2001.

62- Koneru B, Dikdan G. Hepatic steatosis and liver transplantation current clinical and experimental perspectives. Transplantation. 2002 Feb 15;73(3):325-30.

63- Caraceni $P$, Nardo B, Domenicali M, Turi P, Vici M, Simoncini M, De Maria N,Trevisani F, Van Thiel DH, Derenzini M, Cavallari A, Bernardi M. Ischemiareperfusion injury in rat fatty liver: role of nutritional status. Hepatology. 1999 Apr;29(4):1139-46.

64- McLean AE. Hepatic failure in malnutrition. Lancet. 1962 Dec 22;2:1292-4.

65- Truswell AS, Hansen JD, Watson CE, Wannenburg P. Relation of serum lipids and lipoproteins to fatty liver in kwashiorkor. Am J Clin Nutr. 1969 May;22(5):56876.

66- Flores H, Pak N, Maccioni A, Monckeberg F. Lipid transport in kwashiorkor. Br J Nutr. 1970 Dec;24(4):1005-11.

67- Iputo JE, Wong WW, Klein PD. Impaired dietary lipid oxidation in kwashiorkor. Nutr Res. 1998; 18:1187-201.

68- Badaloo A, Reid M, Soares D, Forrester T, Jahoor F. Relation between liver fat content and the rate of VLDL apolipoprotein B-100 synthesis in children with protein-energy malnutrition. Am J Clin Nutr. 2005 May;81(5):1126-32. 
69- Natarajan SK, Basivireddy J, Ramachandran A, Thomas S, Ramamoorthy P, Pulimood AB, Jacob M, Balasubramanian KA. Renal damage in experimentallyinduced cirrhosis in rats: Role of oxygen free radicals. Hepatology. 2006 Jun;43(6):1248-56.

70- Oliveira CPMS, Coelho AMM, Barbeiro HV, Lima VMR, Soriano F, Ribeiro C, Molan NAT, Alves VAF, Souza HP, Machado MCC, Carrilho FJ. Liver mitochondrial dysfunction and oxidative stress in the pathogenesis of experimental nonalcoholic fatty liver disease. Braz J Med Biol Res. 2006 Feb; 39(2):189-194.

71- Glantzounis GK, Yang W, Koti RS, Mikhailidis DP, Seifalian AM, Davidson BR. Continuous infusion of $\mathrm{N}$-acetylcysteine reduces liver warm ischaemiareperfusion injury. Br J Surg. 2004 Oct;91(10):1330-9.

72- Kimura H, Katsuramaki T, Isobe M, Nagayama M, Meguro M, Kukita K, Nui A, Hirata K. Role of inducible nitric oxide synthase in pig liver transplantation. J Surg Res. 2003 May 1;111(1):28-37.

73- Hsu CM, Wang JS, Liu CH, Chen LW. Kupffer cells protect liver from ischemiareperfusion injury by an inducible nitric oxide synthase-dependent mechanism. Shock. 2002 Apr;17(4):280-5.

74- Hines IN, Kawachi S, Harada H, Pavlick KP, Hoffman JM, Bharwani S, Wolf RE, Grisham MB. Role of nitric oxide in liver ischemia and reperfusion injury. Mol Cell Biochem. 2002 May-Jun;234-235(1-2):229-37.

75- Pryor WA, Squadrito GL. The chemistry of peroxynitrite: a product from the reaction of nitric oxide with superoxide. Am J Physiol. 1995 May;268(5 Pt 1):L699-722. 
76- Stewart AG, Barker JE, Hickey MJ. Nitric oxide in ischemia-reperfusion injury. In: Grace PA, Mathie RT, editors. Ischemia-reperfusion injury. $1^{\text {st }}$ ed. Oxford: Blackwell Science, 1999, p 180-95.

77- Serracino-Inglott F, Virlos IT, Habib NA, Williamson RC, Mathie RT. Differential nitric oxide synthase expression during hepatic ischemia-reperfusion. Am J Surg. 2003 Jun;185(6):589-95. 